NOTICE: This is the author's version of a work that was accepted for publication in Economic Analysis and Policy. Changes resulting from the publishing process, such as peer review, editing, corrections, structural formatting, and other quality control mechanisms may not be reflected in this document. Changes may have been made to this work since it was submitted for publication. A definitive version was subsequently published in Economic Analysis and Policy, Vol. 44, Issue 4. (2014). http://doi.org/10.1016/j.eap.2014.11.002 


\title{
Does Oil Price Volatility Matter for Asian Emerging Economies?
}

\author{
Shuddhasattwa Rafiq ${ }^{\mathrm{a}}$ \\ Deakin Graduate School of Business \\ Faculty of Business \& Law \\ Deakin University \\ 221 Burwood Highway, Melbourne, \\ Victoria 3125 Australia \\ Shuddhasattwa.Rafiq@deakin.edu.au \\ $\&$ \\ Ruhul Salim ${ }^{\mathrm{b} *}$ \\ School of Economics and Finance \\ Curtin Business School, \\ Curtin University, \\ Perth, WA 6845, Australia. \\ Curtin University \\ E-mail: Ruhul.Salim@cbs.curtin.edu.au
}

Acknowledgement: The authors are grateful to the two anonymous referees and the editor of this journal for valuable insights and recommendations that significantly improved the quality and presentation of the paper. The authors are solely responsible for any remaining errors.

* Corresponding Author: School of Economics \& Finance, Curtin Business School, Curtin University, Perth, WA 6845. Phone: +61 89266 4577, Fax: +61 89266 3026, E-mail: Ruhul.Salim@cbs.curtin.edu.au 


\title{
Does Oil Price Volatility Matter for Asian Emerging Economies?
}

\begin{abstract}
This article investigates the impact of oil price volatility on six major emerging economies in Asia using time-series cross-section and time-series econometric techniques. To assess the robustness of the findings, we further implement such heterogeneous panel data estimation methods as Mean Group (MG), Common Correlated Effects Mean Group (CCEMG) and Augmented Mean Group (AMG) estimators to allow for cross-sectional dependence. The empirical results reveal that oil price volatility has a detrimental effect on these emerging economies. In the short run, oil price volatility influences output growth in China and affects both GDP growth and inflation in India. In the Philippines, oil price volatility impacts inflation, but in Indonesia, it impacted both GDP growth and inflation before and after the Asian financial crisis. In Malaysia, oil price volatility impacts GDP growth, although there is notably little feedback from the opposite side. For Thailand, oil price volatility influenced output growth prior to the Asian financial crisis, but the impact disappeared after the crisis. It appears that oil subsidization by the Thai Government via introduction of the oil fund plays a significant role in improving economic performance by lessening the adverse effect of oil price volatility on macroeconomic indicators.
\end{abstract}

Keywords: Oil price volatility, Cross-sectional dependence, Bayesian VAR, Generalized impulse response functions, Generalized variance decompositions.

JEL Classification: C32, Q43, O13 


\section{Does Oil Price Volatility Matter for Asian Emerging Economies?}

\section{Introduction}

An impressive body of literature demonstrates that oil price shocks exert adverse impacts on economies from both the supply and demand sides (see Hamilton (1983); Loungani (1986); Mory (1993); Brown and Yucel (2002); Jimenez-Rodriguez (2008); Jbir and Zouari-Ghorbel (2009) etc.). Alternatively, large increases or decreases in oil price variability (i.e., oil price volatility) might adversely affect the economy in the short run by delaying business investment by raising uncertainty (Bernanke 1983) or by inducing costly sectoral resource reallocation (Hamilton 1988). Hence, previous research on oil prices and economic activities has primarily investigated two different aspects of the relationship between oil price and economic activities: the impact of oil price shocks and the impact of oil price volatility. These two approaches differ in the manner in which they incorporate oil price into their models. The first approach takes oil prices at their levels, and the second approach employs different volatility measures to capture the oil price uncertainty.

In contrast to the large number of studies that analyze the impact of oil price shocks, papers that investigate the impact of oil price volatility on economic activities are rather limited and originate from the increase in oil price volatility that occurred in the mid-1980s. Furthermore, studies that identify the impact of oil price volatility in the context of developing nations are almost non-existent in the literature. One exception is the work of Rafiq, Salim, and Bloch (2009) in which the authors analyzed the impact of oil price volatility on the Thai economy. Nevertheless, in light of increasing demand for oil from developing nations, comprehensive studies on the impact of oil price volatility on major developing economies are warranted. This paper attempts to fill this research gap in the oil price-output literature. Although Rafiq, Salim, and Bloch (2009) studied only the Thai economy, this study analyses the impact of oil price volatility on six emerging Asian economies, namely, China, India, Indonesia, Malaysia, the Philippines, and Thailand.

The remainder of the paper is organized as follows. Section 2 elaborates on two different channels through which oil price volatility may impact the macro-economy. Section 3 presents a critical review of earlier literature followed by description of an analytical framework in Section 4. Empirical results from the estimation are presented in Section 5, and conclusions and policy implications are offered in the final section. 


\section{Macroeconomic Implications of Oil Price Volatility}

Findings from studies that investigate the impact of oil price shocks on macro-economies are mixed. A large body of empirical and theoretical literature that analyze the impacts of the oil shocks of 1970s claim that oil price shocks exert adverse impacts on different macroeconomic indicators by raising production and operational costs (Hamilton (1983), Burbridge \& Harrison (1984), Gisser \& Goodwin (1986), Mork (1989), Jones \& Kaul (1996), Shiu-Sheng Chen \& Chen (2007), etc.). However, recent studies argue that the effects of oil price shocks on macroeconomic variables such as inflation are not as large and significant as they were in the 1970s because producers have continuously substituted away from oil over time (e.g., Hooker, 2002; Bachmeier and Cha, 2011; Katayama, 2013).

Alternatively, large oil price changes, i.e., either increases or decreases (volatility), may affect the economy adversely because they delay business investment by raising uncertainty or by inducing costly sectoral resource reallocation. Bernanke (1983) offers a theoretical explanation for the uncertainty channel by demonstrating that if firms experience increased uncertainty relative to the future price of oil, then it is optimal for them to postpone irreversible investment expenditures. If a firm is confronted with a choice of whether to add energy-efficient or energy-inefficient capital, increased uncertainty born by oil price volatility raises the option value associated with waiting to invest. As the firm waits for more updated information, it forgoes returns obtained by making an early commitment, but the chances of making the right investment decision increase. Thus, as the level of oil price volatility increases, the option value rises, and the incentive to investment declines (Ferderer 1996). The downward trend in investment incentives ultimately transmits to different sectors of the economy.

Hamilton (1988) discusses the sectoral resource allocation channel. In this study, by constructing a multi-sector model, the author demonstrates that relative price shocks can lead to a reduction in aggregate employment by inducing workers in the adversely affected sectors to remain unemployed while waiting for conditions to improve in their own sector rather than moving to other positively affected sectors. Lilien (1982) extends Hamilton's work further by showing that aggregate unemployment rises when relative price shocks become more variable.

\section{Oil Price Volatility and the Economy}

Previous research on the oil price-economy relationship has primarily investigated two different aspects of the linkage between oil price and economic activities, i.e., the impact of oil price shock and the impact of oil price volatility. These two approaches differ in the way that they incorporate oil price into their model. The first approach takes oil prices at their 
levels, and the second approach employs different volatility measures to capture the oil price uncertainty.

In response to two consecutive oil price shocks in the early and late 1970s, a considerable number of studies examined the impact of shocks in oil price levels on economic activities. This huge list of studies was pioneered by Hamilton (1983) and extended by Burbridge and Harrison (1984), Gisser and Goodwin (1986), Mork (1989), Mork and Olsen (1994), Cunado and Gracia (2005), Huang, Hwang, and Peng (2005), Lardic and Mignon (2006), Chen and Chen (2007), Huntington (2007), Cologni and Manera (2008), Hamilton (2008), Chen (2009), Jimenez-Rodriguez (2009), Jbir and Zouari-Ghorbe (2009), and several others. Among the impressive body of literature on the oil price and economy relationship, studies such as Mork (1989), Jimenez-Rodriguez and Sanchez (2005) and Farzanegan and Markwardt (2009) indicate that for certain economies, this impact of oil price on economic activities is asymmetric, i.e., the negative impact of oil price increases is larger than the positive impact of oil price decreases. In a recent paper, Omojolaibi (2013) finds that domestic policies rather than oil-booms should be blamed for inflation in Nigeria. This paper employs the structural vector autoregressive (SVAR) technique on inflation, output, money supply and oil prices from 1985:Q1 to 2010:Q4. Another recent trend in the oil price literature looks at structural breaks in the price data. One such paper is that of Salisu and Fasanya (2013) in which the authors implement two different structural break tests in the WTI and Brent oil prices and identify two structural breaks that occurred in 1990 and 2008 that coincidentally correspond to the Iraqi/Kuwait conflict and the global financial crisis, respectively.

In contrast to the above studies that analyze the impact of oil price shocks, articles that investigate the impact of oil price volatility on the economies are quite limited and originate from the increase in oil price volatility from the mid-1980s. Lee, et al. (1995) find that oil price changes have a substantial impact on the economic activities of the US (notably GNP and unemployment) only when prices are relatively stable rather than highly volatile or erratic. Ferderer (1996) analyzes the US data spanning from 1970:01 to 1990:12 to assess whether the relationship between oil price volatility and macroeconomic performance is significant. In this study, the oil price volatility is measured using the simple standard deviation, and the paper concludes that sectoral shocks and uncertainty channels offer a partial solution to the asymmetry puzzle between oil price and output.

Using the measure of realized volatility constructed from daily crude oil future prices traded on the NYMEX (New York Mercantile Exchange), Guo and Kliesen (2005) find that over the period 1984-2004, oil price volatility had a significant effect on various key US 
macroeconomic indicators, i.e., fixed investment, consumption, employment, and the unemployment rate. The findings suggest that changes in oil prices are less significant than the uncertainty in future prices. It should be noted that all of the abovementioned studies on identifying the impact of oil price volatility were undertaken with respect to the US economy. One recent paper that investigates the impact of oil price volatility in the context of developing economies is Rafiq, Salim \& Bloch (2009).

Rafiq, Salim \& Bloch (2009) investigate the impact of oil price volatility on key macroeconomic variables in Thailand using vector auto-regression systems. The variables used for this purpose were oil price volatility, GDP growth, investment, unemployment, inflation, interest rate, trade balance and the budget deficit of Thailand for the period 1993:1 to 2006:4. The oil price volatility data are constructed using the realized volatility measure. Because the structural break test indicates breaks during the Asian financial crisis, this study employs two different VAR systems, one for the entire period and the other for the period after the crisis. For the entire time period, the causality test together with impulse response functions and variance decomposition tests indicate that oil price volatility has a significant impact on unemployment and investment. However, the empirical analysis for the post-crisis period shows that the impact of oil price volatility is transmitted to the budget deficit. This study nevertheless suffers from several theoretical and empirical flaws. First, given the small data set, this study includes too many variables, which may cause model misspecification issues. Second, consideration of such variables as output, employment, and investment within the same model with few data points may raise multi-collinearity issues. Third, performance of a structural break test on a stationary series does not add any value to the overall empirical performance of the study. Fourth, this study employs orthogonalized forms of impulse response functions and variance decompositions, the results from which are sensitive to the ordering of variables. Hence, this study includes only two macroeconomic variables in the model that may indicate the overall macroeconomic performance of the economies, namely, GDP growth and inflation. Furthermore, this study employs a generalized version of the impulse response functions and variance decompositions tests, which provide more robust results in small samples and are not sensitive to the ordering of the variables.

Certain observations can be made from the above discussion on the relationship between oil prices and/or volatility and the economy. First, evidence exists that oil price shocks have an important impact on such aggregate macroeconomic indicators as GDP, interest rates, investment, inflation, unemployment and exchange rates. Second, the evidence generally suggests that the impact of oil price changes on the economy is asymmetric, i.e., the negative impact of oil price increases is larger than the positive impact of oil price decreases. 
Finally, a few academic studies have been carried out to analyze the impact of oil price volatility per se on economic activities, and more importantly, such studies are conducted almost exclusively in the context of developed countries, especially the US. The current study fills that gap in the oil price-economy nexus in the literature.

\section{Data sources and analytical framework}

(a) Data: This study uses quarterly data on three different variables, namely, oil price volatility, GDP growth and inflation. The data periods covered for China, India, Indonesia, Malaysia, the Philippines and Thailand are 2000:2 to 2013:1, 1997:1 to 2013:21, 1993:2 to 2013:4, 1991:2 to 2013:3, 1986:1 to 2013:3, and 1993:2 to 2013:3, respectively. The GDP growth rates and inflation data are given in terms of quarter-to-quarter change based on real GDP and CPI data. For China, real GDP is constructed from nominal GDP. The nominal GDP, GDP deflator, and CPI data are collected from IFS CD September 2009, and the base year for real GDP is 2000. For India, the nominal GDP data are collected from Main Economic Indicators (MEI), a publication of Organization for Economic Co-operation and Development (OECD). Data on GDP deflators are collected from International Financial Statistics (IFS). Both nominal GDP and GDP deflators are given in units of Million Indian Rupees. Real GDP data with a base year of 2005 are calculated by adjusting nominal GDP with deflators. CPI data are also extracted from IFS based on units of Million Indian Rupees.

For Indonesia, real GDP data with the base year of 2005 are collected from Main Economic Indicators (MEI) by OECD. The unit for real GDP is Billion Indonesian Rupiahs. The CPI for Indonesia is collected from IFS. With respect to Malaysia, all of the relevant data for nominal GDP, GDP deflator and CPI are collected from IFS, and the base year for the GDP deflator and CPI is 2005. The scale for all series is given in Million Malaysian Ringgits.

The nominal GDP, GDP deflator and CPI data for the Philippines are also found from IFS, and the base year for the GDP deflator and CPI is 2005. The scale for all series is given in Million Philippines Pesos. Similar to Malaysia and the Philippines, all three series for Thailand are collected from IFS. The base year for GDP Deflator and CPI is 2005. The real GDP of all the concerned countries are not seasonality adjusted.

Realized Oil Price Variance: Based on the nature of the data under consideration and various volatility measures, both parametric and non-parametric (i.e., historical volatility (HS), stochastic volatility (SV), implied volatility (IV), realized volatility (RV) and conditional volatility $(\mathrm{CV})$ ) models have been suggested in the literature. The parametric models can reveal well documented time-varying and clustering features of conditional and implied volatility. However, the validity of the estimate relies to a great extent on the model specifications together with the particular distributional assumptions, and in the instances of 
implied volatility, another assumption with respect to the market price of volatility risk must be met (Andersen et al. 2001a, ABDE hereafter). This stylized fact is also unveiled in a seminal article by Andersen et al. (2001b, ABDL hereafter), which argues that the existence of multiple competing parametric models notes the problem of misspecification. Moreover, the conditional volatility (CV) and stochastic volatility (SV) models are difficult to adopt in a multivariate framework for most practical applications.

An alternative measure of volatility, referred to as realized volatility, is introduced by ABDE (2001 a) and ABDL (2001 b, 2003). Furthermore, the theory of quadratic variation suggests that under the appropriate conditions, realized volatility is an unbiased and highly efficient estimator of volatility of returns, as shown in ABDL (2001 and 2003), and Barndorff-Nielsen \& Shephard (2002, 2001). In addition, by treating volatility as observed rather than latent, the approach facilitates modeling and forecasting using simple methods based on observable data (ABDL, 2003).

According to Andersen et al. (2004), realized volatility or realized variance is the summation of intra-period squared returns

$$
R V_{t}(h) \equiv \sum_{i=1}^{t / h} r_{t-1+i h}^{(h) 2}
$$

where the $h$-period return (in this study, this is the daily oil price return) is given by $r_{t}^{(h)}=\log \left(S_{t}\right)-\log \left(S_{t-h}\right), t$ is the total number of working days in a quarter and $h$ is 1 because this study uses daily price data. Hence, $1 / h$ is a positive integer. In accordance with the theory of quadratic variation, the realized volatility $R V_{t}(h)$ converges uniformly in probability to $I V_{t}$ as $h \rightarrow 0$, and as such, allows for ever more accurate nonparametric measurements of integrated volatility. Furthermore, Zhang et al. (2005) and Aït-Sahalia et al. (2005) state that the realized variance is a consistent and asymptotically normal estimator once suitable scaling is performed.

In calculating the quarterly volatility measure, the daily crude oil prices of "Arab Gulf Dubai FOB \$US/BBL" are considered and transformed into local prices by adjusting the world oil prices with the respective foreign exchange rates. The Dubai oil prices are collected from Datastream, and the source is ICIS (Independent chemical information service) Pricing and exchange rates for different currencies are also taken from Datastream, and the source is GTIS-FTID.

Because this study addresses quarterly data, at the outset of empirical analyses, the authors decomposed the observed data into trend, seasonal and idiosyncratic or random components. Graphical representations of the decomposed data are shown below in Figure 1. 
These figures reveal two important facts: (i) crude oil prices have been highly volatile in recent years, particularly in the second half of the 1990s, and (ii) because none of the variables are seasonally adjusted, signs of seasonality appear in all data series for all of the countries. Hence, this study performs seasonal adjustment for the GDP growth data of all countries.

The seasonal adjustment is carried out by implementing the U.S. Census Bureau's X12 seasonal adjustment program. The X11 additive method together with the default X12 seasonal filter was adopted for this task.

\section{[Figure 1 could be here]}

From visual scrutiny of the decomposed series together with the realized volatility and inflation data, it can be inferred that with respect to most of the series for Indonesia, Malaysia and Thailand, spikes occur near the period of the Asian financial crisis, i.e., from early 1997 to mid-1998. This observation is not unusual given that these three economies were among the most severely affected during the crisis period. In addition, all of the variables appear to be stationary at levels.

Summary statistics of all variables and for the entire time-series cross-section indicate that GDP growth rate, oil price volatility and inflation are significantly correlated for most of the countries. ${ }^{1}$ Another significant finding is that for most of the countries, GDP growth is negatively correlated and inflation is positively correlated with the oil price volatility. Prior to identifying causality among the variables, an investigation of time-series properties of the data is warranted, and the following section discusses these properties.

(b) Methodology: This article employs both time-series cross-section and time-series analyses such that the linkages among the studied variables are identified for the entire panel as well as for individual countries. In addition to examining the panel behavior, it is worth looking at the country level because each of these developing countries contains certain country-specific dynamics. This study also implements contemporary second-generation panel data estimation procedures for heterogeneous slope coefficients under cross-sectional dependence to check the robustness of the results.

With respect to time-series cross-section, this study investigated the following equation:

$$
\operatorname{ggdp} p_{i t}=\beta_{1 i} r v_{i t}+\beta_{2 i} \inf _{i t}+v_{1 i}+\varepsilon_{1 i t}
$$

where $g g d p, r v$ and inf denote GDP growth, oil price volatility and inflation, respectively. Countries are indicated by the subscript $i(i=1,2, \ldots ., N)$, and the subscript $t(t=1,2, \ldots, T)$

\footnotetext{
${ }^{1}$ Results not reported due to space limitation. However, results will be provided upon request.
} 
indicates the time period. Country-specific effects are included through $v_{i}$, and $\varepsilon_{i t}$ represents the random error term. This study implements Pesaran's (2004) cross-sectional dependence. Cross-section dependence can pose serious problems in testing the null hypothesis of the unit root (Westerlund and Breitung 2013). Thus, much effort has been invested in development of the commonly known 'second-generation' test procedures that are robust to such dependencies. The cross-section augmented Dickey-Fuller (CADF) and Im et al. (2003) CIPS of Pesaran (2007) are two of the most popular second-generation panel unit root tests available. Although the small-sample property of these tests has been inspected by Gengenbach et al. (2009), De Silva et al. (2009) and others, Westerlund et al. (2013) has scrutinized the local power of these tests. Beck and Katz's (2007) Monte Carlo experiments suggest that the random coefficient models give superior estimates of overall $\beta$, whether or not significant unit heterogeneity exists, and also provide good estimates of the unit $\beta_{i}$. Hence, this study performs random coefficient regression to identify the overall $\beta$ for the given time-series-cross-section data.

To check the robustness of the time-series-cross-section estimations, this study further implements panel estimation procedures. If we assume a homogeneous panel, then the above models (Equation 1) can be estimated within the standard panel regression techniques, i.e., pooled OLS (POLS) and various fixed effects (FE), random effect (RE), or Generalized Method of Moments (GMM) specifications (Sadorsky, 2014). Nonetheless, the assumption that all of the factors affecting GDP growth in our model (i.e., oil price volatility and inflation) across all of the six studied countries are homogenous is quite unrealistic. Moreover, in our panel setting, we have included countries from different economic, social and cultural backgrounds. Contemporary models with heterogeneous slope coefficients can be estimated using mean group (MG) estimators (Pesaran, 1997; Pesaran and Smith, 1995) or variants of MG estimators. In addition to allowing for heterogeneous slope coefficients across group members, these estimators also account for correlation across panel members (crosssectional dependence). To implement these models, i.e., Mean Group estimator of Pesaran and Smith (1995), Pesaran's (2006) Common Correlated Effects Mean Group (CCEMG) estimator, the Augmented Mean Group (AMG) due to Eberhardt and Teal (2010) and Bond and Eberhardt (2009), we estimate a dynamic panel of the following form:

$$
g g d p_{i t}=\alpha_{1 i} g g d p_{i t-1}+\alpha_{2} r v_{i t}+\alpha_{3 i} r v_{i t-1}+\alpha_{4} \inf _{i t}+\alpha_{5} \inf _{i t-1}+\rho_{1 i}+\varepsilon_{1 i}
$$

The authors appreciate the fact that there are many country-specific factors that must be considered, especially for emerging countries in which the economic cycles move quite rapidly. Hence, this paper further implements time series analyses for individual countries. For this purpose, this study performs the Granger causality test to examine the causal 
relationships among oil price volatility, output growth, and inflation of six major emerging economies of Asia.

Vector Auto-regression (VAR) of the following form is considered for this purpose:

$$
\begin{aligned}
& Y_{t}=\alpha_{0}+\sum_{i=1}^{n} \beta_{i} Y_{t-i}+\sum_{i=1}^{n} \lambda_{i} X_{t-i}+\mu_{t} \\
& X_{t}=\phi_{0}+\sum_{i=1}^{n} \varphi_{i} Y_{t-i}+\sum_{i=1}^{n} \eta_{i} X_{t-i}+v_{t}
\end{aligned}
$$

where $\mathrm{n}$ is the number of the optimum lag length. In this study, the optimum lag lengths are determined empirically by the Schwarz Information Criterion (SIC). For each equation in the above VAR, Wald $\chi^{2}$ statistics are used to test the joint significance of each of the other lagged endogenous variables in the equation. In addition, the Wald $\chi^{2}$ statistics tell us whether an endogenous variable can be treated as exogenous. Moreover, the roots of the characteristics polynomial test are applied to confirm whether the VAR system satisfies the stability condition.

The conventional Granger causality test based on the standard VAR is conditional on the assumption of stationarity of the variables that constitute the VAR. This study employs the Augmented Dickey-Fuller $(A D F)$, Philips-Perron $(P P)$, and Kwiatkowaski-PhilipsSchmidt-Shin (KPSS) unit root tests for this purpose. The combined use of these tests makes it possible to test for both the null hypotheses of non-stationarity and stationarity. This process of joint use of the unit root $(A D F$ and $P P)$ and stationarity (KPSS) tests is known as confirmatory data analysis (Brooks 2002).

The Granger causality test suggests which variables in the models have significant impacts on the future values of each of the variables in the system. However, the result will not, by construction, be able to indicate how long these impacts will remain effective in the future. Variance decomposition and impulse response functions give this information. Hence, this paper conducts generalized variance decompositions and generalized impulse response functions analyses proposed by Koop et al (1996) and Pesaran and Shin (1998). The unique features of these approaches are that the results from these analyses are invariant to the ordering of the variables entering the VAR system and provide more robust results for small samples. Impulse response functions trace the responsiveness of the dependent variable in the VAR system to a unit shock in error terms. Variance decomposition gives the proportions of the movement in the dependent variables that are due to their "own" shocks versus shocks to the other variables. 


\section{Analyses and Findings:}

(a) Time-Series Properties of Data: This study performs three different unit root tests, namely, the Augmented Dickey-Fuller (ADF), Phillips-Perron (PP) and KwiatkowskiPhillips-Schmidt-Shin (KPSS) unit root tests. ${ }^{2}$ According to the results of the unit root tests, it can be inferred that all three series for all countries are stationary at their levels. ${ }^{3}$ The graphical representations of the variables reveal a number of spikes in the applicable variables for Indonesia, Malaysia and Thailand during the Asian financial crisis. Thus, this study performs two different VAR analyses for these three countries; one VAR analysis is performed for the whole time period, and another VAR analysis is performed for the period after the crisis, i.e., from the fourth quarter of 1998 after which the impact of the crisis seems to diminish. Findings from the VAR analyses for each of the countries are in order.

Recently, Bayesian VAR methods have become popular because the use of prior information provides a formal avenue for shrinking parameters. Working with large and medium Bayesian VARs, Banbura et al. (2010) and Koop (2013) found that Bayesian VARs tend to provide better forecasts than factor methods and that the simple Minnesota prior forecasts perform well in medium and large VARs. Therefore, these methods are attractive relative to computationally more demanding alternatives. Hence, this paper implements Bayesian VAR and uses forecasting tools such as the Generalized Impulse Responses and Variance Decomposition methods within the Bayesian VAR system.

(b) Impact of Oil Price Volatility on Economic Activities - A Simple Time-Series Cross-Section Exercise: This sub-section provides an overview of the panel behavior of GDP growth, oil price volatility and inflation. Before applying econometric tests, the authors measure simple correlations. The measures indicate that although the correlation between volatility and inflation is positive, correlations between oil price volatility and GDP growth and between volatility inflation and growth are negative. ${ }^{4}$

Beginning with the time-series-cross-section econometric exercise, this study proceeds to formalize this process by checking the stationarity properties of the variables to avoid the danger of spurious relationships among the variables. This study implements both IM-Pesaran-Shin and Fisher-type unit root tests and does not accept the null of nonstationarity. ${ }^{5}$ Unit root tests that assume cross-sectional independence can suffer from a lack of power if estimated on a time-series cross-section that contains cross-sectional dependence. To account for such possibility, Pesaran's (2004) cross-section dependence (CD) test is

\footnotetext{
${ }^{2}$ Same as footnote 1.

${ }^{3}$ This result is expected because both GDP growth and inflation have already been differenced and RV is the sum of the squares of price returns.

${ }^{4}$ Same as footnote 1 .

${ }^{5}$ Same as footnote 1 .
} 
implemented. The CD tests for each of the variables indicate that all exhibit cross-section dependence (Table 1). This study therefore implements Pesaran's (2007) CIPS (Z(t-bar)) test for unit roots, a unit root test that allows for cross-sectional dependence. These tests are estimated with a constant term and two lags. The CIPS test also indicates that each of the series is stationary at its level. Thus, it can be inferred from all of the tests that the variables involved do not contain unit roots.

\section{[Table 1 could be here]}

Once it has been revealed that the series are stationary and that regression carried out will not be spurious, this study performs simple random coefficient time-series cross-section regression to identify the dynamic relationships among variables. The results of the random coefficient models are reported in Table 2.

The results from the random coefficient regression models suggest that oil price volatility and inflation have significant negative impacts on GDP growth. To check the robustness of the results from the time-series cross-section estimations, we implement contemporary models with heterogeneous slope coefficients that can be estimated using mean group (MG) estimators (Pesaran, 1997; Pesaran and Smith, 1995) or variants of MG estimators.

(c) Impact of Oil Price Volatility on Economic Activities - Second generation panel estimation: As indicated by the second, third and fourth columns of Table 2, all three panel data models confirm the findings from time-series-cross-section analyses that both oil price volatility and inflation significantly influence GDP in a negative manner.

\section{[Table 2 could be here]}

(d) Impact of Oil Price Volatility on Economic Activities - Time Series Analyses: This subsection separately discusses the impacts of oil price volatility on each economy. For Indonesia, Malaysia and Thailand, which are the countries most affected countries by the financial crisis, two different VAR systems are employed to investigate and compare the impact of oil price volatility on economic activities for the entire time period and for the period after the crisis. For China, India and the Philippines, which are the least affected economies, one VAR analysis is performed for the entire time period.

In selecting the appropriate lag length, the Schwarz Information Criterion (SIC) VAR lag order selection criteria were consulted. Because we use quarterly data for this study, the maximum lag length provided in lag selection test is 6 . The test for stability of the VAR systems is carried out, and the inverse characteristic roots of the auto-regressive (AR) polynomial indicate that all of the VARs with the suggested lags are appropriate for 
investigating the relationships between volatility of oil prices and other applicable macroeconomic indicators. Although the Granger causality tests are performed within the normal VAR system, the Generalized Impulse Response and Variance Decomposition forecasting tests are performed within the Bayesian VAR environment.

\section{5.c.1 Impact analysis for China}

According to the Bayesian VAR result of China, the coefficients and t-statistics for most of the lags in the GDP growth equation reveal that oil price volatility appears to have a negative impact on GDP growth [Appendix Table 2]. The Granger causality tests are consulted to determine the direction of causality among the variables. The results of the Granger causality tests for China are reported in Appendix Table 1. The causality tests reveal that in China, a bi-directional causality exists between oil price volatility and GDP growth. In addition, a bidirectional causality also exists between GDP growth and inflation.

The results of the impulse response functions are presented in Appendix Figure 1. According to the figures, in response to a one S.E. shock on the realized volatility of oil prices, GDP growth instantly becomes negative, and after a one-quarter time horizon, the response appears to diminish. Furthermore, in response to a one S.E. shock in GDP growth, inflation responds positively before it diminishes after three quarters.

In response to a one S.E. shock in inflation, GDP growth rises during the first quarter, and from the second-quarter time horizon, the response appears to die down and persist horizontally into the future. Thus, the impulse response functions of China confirm most of the findings from the causality test except for the causality of GDP growth and oil price volatility. Thus, according to the impulse response functions, oil price volatility has a shortterm negative impact on GDP growth in China.

The results of variance decompositions are presented in Appendix Table 3. According to the results, $17.10 \%$ of the variations in GDP growth can be explained by realized volatility at the end of five quarters, but this figure goes up to $20.90 \%$ after twenty quarters. Inflation also explains a fair portion of the variations in output growth. However, $25.50 \%$ of the variation in realized volatility can be explained by GDP growth after five quarters because it decreases to $16.80 \%$ at the end of twenty quarters. The GDP growth explains inflation with an amount of $28.90 \%$ after five quarters, which increases up to $29.70 \%$ at the end of twenty quarters. Hence, the results of variance decomposition analysis also conform to the causality directions that were identified.

Therefore, according to the Bayesian VAR analysis together with the results of the causality test, impulse responses functions and variance decompositions, it can be inferred that in China, oil price volatility impacts GDP growth in the short run, and both GDP growth 
and inflation are strongly tied together. It should be mentioned that due to space limitations, the remainder of this study will provide major findings with respect to different countries for different time periods.

\section{5.c.2 Impact analysis for India}

According to the VAR output for India, it can be inferred that oil price volatility has a significant negative impact on GDP growth and a positive impact on inflation, as indicated by the coefficients and t-statistics of RV in the GDP growth and inflation equations within the VAR system, respectively [Appendix Table 5]. The results from the Granger causality test are presented in Appendix Table 4. The causality test reveals that a bi-directional causality exists between realized volatility and GDP growth. A bi-directional causality is also found between realized volatility and inflation. The causality between GDP growth and inflation is also bi-directional.

The impulse response functions are presented in Appendix Figure 2. The results of variance decomposition are reported in Appendix Table 6. The results of both of these tests are consistent with the Granger causality test results even if the time horizon is expanded to 20 quarters. Hence, according to the VAR analysis for India, it can be inferred that oil price volatility impacts both GDP growth and inflation in the Indian economy. Furthermore, both GDP growth and inflation are closely related.

\section{5.c.3 Impact analysis for Indonesia}

This study analyses the Indonesian economy based on two different VAR systems for two different time periods. The first time period covers the entire data set, i.e., from 1993:2 to 2013:4, and the second VAR refers to the period after the crisis, i.e., from 1998:4 to 2013:4. These two VARs are implemented to capture any significant change in the impact analysis due to the Asian financial crisis.

From the Bayesian VAR results, the coefficients and t-statistics for RV in the GGDP growth and inflation equations indicate a negative link between oil price volatility and GGDP growth and a positive relationship between inflation and oil price volatility [Appendix Table 8]. The results of the Granger causality test are reported in Appendix Table 7.

According to the results, the oil price volatility Granger causes both GDP growth and inflation, whereas only inflation causes volatility in oil prices. Moreover, a bi-directional causality exists between GDP growth and inflation. The impulse response functions (IRF) are presented in Appendix Figure 3. The results from variance decomposition (VD) analysis are reported in Appendix Table 9. In summary, according to the VAR results together with the 
findings from IRF and VD for the entire data period from 1993:2 to 2013:4, different tests within the Bayesian VAR framework for Indonesia reveal that oil price volatility impacts both GDP growth and inflation, and similar to China and India, GDP growth and inflation are closely related. Furthermore, the fact that inflation causes realized volatility maintains that oil price volatility is endogenous to the VAR model.

Next, this study presents the Bayesian VAR outcome for the period after the Asian financial crisis for Indonesia to observe whether any dissimilarity exists in the dynamics of the impact channels. From the coefficients and t-statistics of the realized volatility in the GDP growth and inflation equations of the VAR estimation for the period after the crisis, it can be inferred that oil price volatility exerts a negative impact on GDP growth and a positive impact on inflation even after the financial crisis is over [Appendix Table 11]. The results of the Granger causality test are reported in Appendix Table 10. The Granger causality test further indicates that after the crisis, oil price volatility causes both GDP growth and inflation in Indonesia. In addition, the bi-directional causality between GDP growth and inflation also holds true for the time period after the crisis. However, a significant dissimilarity between two models is that after the crisis, oil price volatility appears to become exogenous in the model because none of the variables seem to cause realized volatility after the Asian financial crisis.

This study further performs impulse response function and variance decomposition analyses to check the robustness of the causality test. The results from impulse response functions are presented in Appendix Figure 4, and the results from the variance decomposition analysis are presented in Appendix Table 12. The findings from the Impulse Responses and Variance Decompositions are consistent with the causality test results in most cases.

Based on two different VAR analyses for Indonesia, it can be inferred that for the Indonesian economy, oil price volatility impacts both GDP growth and inflation for both of the time periods, i.e., for the entire sample period and for the period after the Asian financial crisis. Furthermore, the link between GDP growth and inflation is bi-directional for both of the VAR systems.

\section{5.c.4 Impact analysis for Malaysia}

The data plots for Malaysia portray a spike during early 1997 to mid-1998, and the Malaysian economy was one of the most adversely affected economies during the Asian financial crisis. Thus, Malaysian data are also investigated based on two different VAR systems, one for the entire period from 1991:2 to 2013:3 and the other for the period after the crisis, i.e., from 1998:4 to 2013:3. The Bayesian VAR results for the entire periods indicate that the realized 
volatility negatively impacts output growth in Malaysia [see Appendix Table 14]. The Granger causality test results are presented in Appendix Table 13. According to the causality results, a bi-directional causality exists between oil price volatility and GDP growth, a unidirectional causality runs from inflation to realized volatility, and a bi-directional causality between GDP growth and inflation in Malaysia is observed for the entire period from 1991:2 to $2013: 3$.

The impulse response function findings are presented in Appendix Figure 5, and the results of variance decompositions are reported in Appendix Table 15. According to the VAR results together with impulse response functions and variance decompositions for the entire period, it can be inferred that oil price volatility impacts GDP growth in Malaysia, GDP growth and inflation impact each other, and both GDP growth and inflation have a small impact-realized volatility.

The analysis for the Malaysian economy after the financial crisis begins with the Bayesian VAR estimation [Appendix Table 17]. The coefficients of realized volatility in the GDP growth equation indicate that oil price volatility has a negative impact on the Malaysian output growth. Findings from the causality tests are reported in Appendix Table 16. The causality test results for the period after the crisis are nearly similar to those of the causality test results for the entire period. A bi-directional causality exists between GDP growth and realized volatility, a bi-directional causality exists between inflation and GDP growth, and a uni-directional causality runs from inflation to oil price volatility. The results from the impulse response functions and variance decompositions are presented in Appendix Figure 6 and Appendix Table 18, respectively. All of the tests reveal minor changes in the two VAR analyses performed for the Malaysian economy. In both of the VAR systems, oil price volatility impacts GDP growth, but there is little feedback from the opposite side. Furthermore, similar to the other economies analyzed thus far, GDP growth and inflation appear to be strongly tied together in the Malaysian economy.

\section{5.c.5 Impact analysis for the Philippines}

The results from Bayesian VAR estimation reveal that in the Philippines, oil price volatility positively affects inflation [Appendix Table 20]. The results from the Granger causality test are given in Appendix Table 19. The Granger causality test indicates a bi-directional causality between oil price volatility and inflation and also a bi-directional causality between GDP growth and inflation. For the purpose of checking the robustness of the Granger causality test, impulse responses and variance decompositions are implemented. 
The impulse response functions and variance decompositions are presented in Appendix Figure 7 and Appendix Table 21. According to the results from the Bayesian VAR, Granger causality, impulse response and variance decompositions tests, it can be inferred that in the Philippines, oil price volatility impacts inflation and that GDP growth and inflation are closely related in the short run.

\section{5.c.6 Impact analysis for Thailand}

Because the Thai economy also was severely affected by the Asian financial crisis and because the data suggest a spike during the crisis period, similar to Indonesia and Malaysia, this study implements two different VARs for Thailand in a similar fashion. The Bayesian VAR output for the entire period of Thailand indicates that in the Thai economy, GDP growth is significantly impacted negatively by oil price volatility [Appendix Table 23].

The causality test findings for the entire data set are reported in Appendix Table 22. The causality test results indicate that in Thailand, the oil price volatility Granger causes GDP growth and that inflation Granger causes both oil price volatility and GDP growth. The impulse response functions for the entire time period for Thailand are presented in Appendix Figure 8. The results from variance decomposition analysis are reported in Appendix Table 24. For the entire period, all tests within the VAR framework suggest that oil price volatility impacts GDP growth in the Thai economy. Next, this study performs a separate VAR analysis for the period after the Asian financial crisis.

From the Bayesian VAR (2) estimation results for the period from 1998:4 to 2013:3, it appears that the impact of RV on GDP growth becomes insignificant after the financial crisis (Appendix Table 26). The results of the Granger causality test within this time frame are reported in Appendix Table 25. Most of the causal relationship observed for the entire period is absent in these causality test results for the period after the financial crisis, except for the causality tests, which find a bi-directional causality running from inflation to output growth. Furthermore, realized volatility appears to be exogenous to this system.

The impulse response functions for this period after the financial crisis are presented in Appendix Figure 9. The results from the variance decomposition analysis are reported in Appendix Table 27. From the VAR analyses for Thailand, it can be inferred that oil price volatility impacts output growth for the entire period; however, after the Asian financial crisis, the impact seems to disappear. This finding is consistent with that of Rafiq, Salim \& Bloch (2008) in which the authors found that impact of oil price volatility no longer exists in the Thai economy after the financial crisis. 


\section{Conclusions and Policy Implications}

This article investigates the short-term impact of oil price volatility in six emerging economies of Asia. One of the unique features of this paper is that in this work, the oil price volatility for each country is calculated using a non-parametric approach, namely, the realized oil price variance. Furthermore, to the author's best knowledge, this is one of the first studies that analyses the impact of oil price volatility on developing economies. Because Indonesia, Malaysia and Thailand were severely affected by the Asian financial crisis and because the data in this work portray spikes during this period, this study implements two different VAR systems for these countries in an attempt to compare the impact channels for the entire period and for the period after the crisis.

For China, according to the VAR analysis, the Granger causality test, and impulse response functions and variance decompositions, it can be inferred that oil price volatility impacts output growth in the short run. For India, oil price volatility impacts both GDP growth and inflation. In the Philippines, oil price volatility impacts inflation. Furthermore, for all of these economies, GDP growth and inflation are closely related in the short run. Another important feature of the results from these three countries is that for all of the VAR models, oil price volatility appears to be slightly endogenous. This result may be caused by the use of exchange rates in constructing the realized volatility measure.

Based on two different VAR analyses for Indonesia, it can be inferred that for the Indonesian economy, oil price volatility impacts both GDP growth and inflation for both of the time periods, i.e., for the entire sample period and for the period after the Asian financial crisis. Furthermore, the link between GDP growth and inflation is bi-directional for both of the VAR systems. However, one significant difference in the results from the two VARs is that oil price volatility appears to become exogenous to the economy after the financial crisis. Minor differences are observed between the two VAR analyses performed for the Malaysian economy. In both of the VAR systems, oil price volatility impacts GDP growth, but there is a notably little feedback from the opposite side. Furthermore, similar to the other economies analyzed thus far, GDP growth and inflation appear to be strongly tied in the Malaysian economy.

From the VAR analyses for Thailand, it can be inferred that oil price volatility impacts output growth for the entire period. However, after the Asian financial crisis, the impact seems to disappear. This finding is consistent with that of Rafiq, Salim \& Bloch (2008) in which the authors found that impact of oil price volatility no longer exists in the Thai economy after the financial crisis. Thus, the results from after the financial crisis show that the adverse effect of oil price volatility has been mitigated to a certain extent. It appears 
that oil subsidization by the Thai Government via the introduction of the oil fund plays a significant role in improving economic performance by lessening the adverse effect of oil price volatility on macroeconomic indicators. The policy implication of this result is that the government should continue to pursue its policy to stabilize domestic oil prices through subsidization and thus aid in stabilizing economic growth. 


\section{References}

Aït-Sahalia, Yacine, Per A. Mykland, and Lan Zhang. 2005. How often to sample a continuous-time process in the presence of market microstructure noise The Review of Financial Studies 18 (2):351-416.

Andersen, Torben G., Tim Bollerslev, Francis X. Diebold, and Heiko Ebens. 2001 a. The distribution of realized stock return volatility. Journal of Financial Economics 61 (1):43-76.

Andersen, Torben G., Tim Bollerslev, Francis X. Diebold, and Paul Labys. 2001 b. The distribution of realized exchange rate volatility. Journal of the American Statistical Association 96 42-55. 2003. Modeling and forecasting realized volatility. Econometrica 71 (2):579-625.

Andersen, Torben G., Tim Bollerslev, and Nour Meddahi. 2004. Analytical evaluation of volatility forecasts. International Economic Review 45 (4):1079-1110.

Bachmeier, L.J., Cha, I. 2011. Why don't oil shocks cause inflation? evidence from disaggregate inflation data. Journal of Money, Credit, and Banking 43(6), 1165-1183.

Barndorff-Nielsen, Ole E., and Neil Shephard. 2001. Non-Gaussian Ornstein-Uhlenbeck-Based models and some of their uses in financial economics. Journal of Royal Statistical Society, Series B 63 (2):167-241.

- 2002. Econometric analysis of realized volatility and its use in estimating stochastic volatility models. Journal of Royal Statistical Society, Series B 64 (2):253-280.

Beck, Nathaniel and Jonathan N. Katz. 2007. Random coefficient models for time-series-cross-section data: Monte Carlo experiments. Political Analysis 15: 182-195.

Bernanke, Ben S. 1983. Irreversibility, uncertainty, and cyclical investment. Quarterly Journal of Economics 98 (1):85.

Bond, S., Eberhardt, M., 2009. Cross-section dependence in nonstationary panel models: A novel estimator, Paper presented in the Nordic Econometrics Conference in Lund, Sweden.

Brooks, Chris. 2002. Introductory Econometrics for Finance: Cambridge University Press.

Brown, Stephen P. A., and Mine K. Yucel. 2002. Energy prices and aggregate economic activity: an interpretative survey. The Quarterly Review of Economics and Finance 42 (2):193-208.

Burbridge, John, and Alan Harrison. 1984. Testing for the effects of oil price rises using vector autoregressions. International Economic Review 25 (2):459-484.

Chen, Shiu-Sheng. 2009. Oil price pass-through into inflation. Energy Economics 31 (1):126-133.

Chen, Shiu-Sheng, and Hung-Chyn Chen. 2007. Oil prices and real exchange rates. Energy Economics 29 (3):390-404.

Cologni, Alessandro, and Matteo Manera. 2008. Oil prices, inflation and interest rates in a structural cointegrated VAR model for the G-7 countries. Energy Economics 30 (3):856-888.

Cunado, J, and F Perez de Gracia. 2005. Oil prices, economic activity and inflation: Evidence for some asian countries. Quarterly Review of Economics and Finance 45 (1):65-83. 
De Silva, S., K. Hadri and A. R. Tremayne 2009. Panel Unit Root Tests in the presence of crosssectional dependencies: Finite sample performance and an application. Econometric Journal 12: $340-366$.

Eberhardt, M., Teal, F., 2010. Productivity analysis in global manufacturing production, Economics Series Working Papers. University of Oxford.

Gengenbach, C., F. C. Palm and J.-P. Urbain 2009. Panel unit root tests in the presence of crosssectional dependencies: Comparisions and implecations for modelling: Econometric Reviews 29: 111-145.

Hooker, M.A. 2002. Are oil shocks inflationary? asymmetric and nonlinear specifications versus changes in regime. Journal of Money, Credit and Banking 34, 540-561.

Farzanegan, Mohammad Reza, and Gunther Markwardt. 2009. The effect of oil price shocks on the Iranian economy. Energy Economics 31 (1):134-151.

Ferderer, J Peter. 1996. Oil price volatility and the macroeconomy. Journal of Macroeconomics 18 ( 1):1-26.

Gisser, Micha, and Thomas H. Goodwin. 1986. Crude oil and the macroeconomy: Tests of some popular notions. Journal of Money, Credit and Banking 18 (1):95-103.

Guo, Hui, and Kevin L Kliesen. 2005. Oil price volatility and U. S. macroeconomic activity. Review Federal Reserve Bank of St. Louis 57 (6):669-683.

Hamilton, James D. 1983. Oil and the macroeconomy since world war II. Journal of Political Economy 91 (2):228-248.

1988. A neoclassical model of unemployment and the business cycle. Journal of Political Economy 96 (3):593-617.

- 2008. Oil and the Macroeconomy Edited by S. N. Durlauf and L. E. Blume, The New Palgrave Dictionary of Economics: Palgrave Macmillan.

Huang, Bwo-Nung, M. J. Hwang, and Hsiao-Ping Peng. 2005. The asymmetry of the impact of oil price shocks on economic activities: An application of the multivariate threshold model. Energy Economics 27 (3):455-476.

Huntington, Hillard G. 2007. Oil shocks and real U.S. income. The Energy Journal 28 (4):31-46.

Im, K. S., M.H. Pesaran and Y. Shin 2003. Testing for unit roots in heterogeneous pnels. Journal of Econometrics 122: 81-126.

Jbir, Rafik, and Sonia Zouari-Ghorbel. 2009. Recent oil price shock and Tunisian economy. Energy Policy 37 (3).

Jimenez-Rodriguez, Rebeca. 2008. The impact of oil price shocks: Evidence from the industries of six OECD countries. Energy Economics 30 (6):3095-3108.

2009. Oil price shocks and real gdp growth: Testing for non-linearity. The Energy Journal 30 (1):1-23 .

Jimenez-Rodriguez, Rebeca, and Marcelo Sanchez. 2005. Oil price shocks and real GDP growth: Empirical evidence for some OECD countries. Applied Economics 37 (2):201-228. 
Katayama, M. 2013. Declining effects of oil price shocks. Journal of Money, Credit and Banking 45(6), 977-1016.

Koop, G., M. H. Pesaran, and S. M. Potters. 1996. Impulse response analysis in nonlinear multivariate models. Journal of Econometrics 74 (1):119-147.

Lardic, Sandrine, and Valerie Mignon. 2006. The impact of oil prices on GDP in European countries: An empirical investigation based on asymmetric cointegration. Energy Policy 34 (18):39103915.

Lee, Kiseok, Shawn Ni, and R. Ratti. 1995. Oil shocks and the macroeconomy: The role of price variability. The Energy Journal 16 (4):39-56.

Lilien, David M. 1982. Sectoral Shifts and Clynical Unemployment. Journal of Political Economy 90 (4):777-793

Loungani, Prakash. 1986. On price shocks and the dispersion hypothesis. Review of Economics and Statistics 68 (3):536-539.

Mork, Knut Anton. 1989. Oil and the macroeconomy when prices go up and down: An extension of Hamilton's results Journal of Political Economy 97 (3):740-744.

Mork, Knut Anton, and Olstein Olsen. 1994. Macroeconomic responses to oil price increases and decreases in seven OECD countries. Energy Journal 15 (4):19-35.

Mory, Javier F. 1993. Oil prices and economic activity: Is the relationship symmetric? The Energy Journal 14 (4):151-161.

Omojolaibi, Joseph Ayoola 2013. Does Volatility in Crude Oil Price Precipitate Macroeconomic Performance in Nigeria? International Journal of Energy Economics and Policy, Vol. 3, No. 2, 143-152.

Pesaran, M. H. 2007. A simple panel unit root test in the presence of cross section dependence. Journal of Applied Econometrics 22: 265-312.

Pesaran, M.H., 2006. Estimation and inference in large heterogeneous panels with a multifactor error structure. Econometrica 74, 967-1012.

Pesaran, M. H. 2004. General diagnostic tests for cross section dependence in panels. Cambridge Working Papers in Economics, No. 0435. University of Cambridge (June).

Pesaran, M.H., 1997. The role of economic theory in modelling the long run. Econ. J. 107, 178-191.

Pesaran, M. H., and Yongcheol Shin. 1998. Generalized impulse response analysis in linear multivariate models. Economics Letters 58 (17-29).

Pesaran, M.H., Smith, R.P., 1995. Estimating long-run relationships from dynamic heterogeneous panels. J. Eco. 68, 79-113.

Rafiq, Shuddhasattwa, Ruhul Salim, and Harry Bloch. 2009. Impact of crude oil price volatility on economic activities: an empirical investigation in the Thai economy. Resources Policy 34:121-132.

Sadorsky, P., 2014. The effect of urbanization on CO2 emissions in emerging economies. Energy Economics 41, 147-153. 
Salisu, A. A. and Fasanya, O. A (2013). Modelling oil price volatility with structural breaks, Energy Policy, 52: 554-562.

Westerlund, J., and Breitung 2013. Lessons from a decade of IPS and LLC. Econometric Reviews 32: 547-591.

Westerlund, J., M. Hosseinkouchack, and M. Solberger 2014, The local power of the CADF and CIPS panel unit root tests, Econometric Reviews (forthcoming).

Zhang, Lan, Per A. Mykland, and Yacine Ait-Sahalia. 2005. A tale of two time scales: Determining integrated volatility with noisy high-frequency data. Journal of the American Statistical Association 100 (472):1394-1411. 
Table 1: Tests for Cross-Section Dependence and Panel Unit Roots

\begin{tabular}{ccccccc}
\hline Series & CD-test & p-value & Corr & Abs(corr) & CIPS & p-value \\
\hline GGDP & 4.188 & 0.000 & 0.190 & 0.513 & 0.246 & 0.014 \\
RV & 9.022 & 0.000 & 0.434 & 0.931 & 0.053 & 0.000 \\
INF & 9.022 & 0.000 & 0.025 & 0.514 & 0.134 & 0.009 \\
\hline
\end{tabular}

Table 2: Time-Series-Cross-Section and Panel Estimations

\begin{tabular}{lcccc}
\hline \multicolumn{2}{l}{ Time-series-cross-section estimates } & Panel estimates & & \\
\hline Equations/Series & Random-effects & Mean Group & Correlated Effects MG & Augmented Mean \\
& GLS regression & $(\mathrm{MG})$ & estimator (CCEMG) & Group (AMG) \\
\hline Dependent Variable- GGDP & & & $-16.506(0.048)$ & $-7.091(0.003)$ \\
RV & $-10.409(0.031)$ & $-11.001(0.009)$ & $-0.076(0.002)$ & $-0.216(0.054)$ \\
INF & $-0.1699(0.013)$ & $-0.194(0.067)$ & & \\
\hline
\end{tabular}

Note: $p$-values are in the parenthesis. No. of observations $=484$. For panel estimation models, elasticities are based on Pesaran and Smith (1995) Mean Group estimator, Pesaran (2006) Common Correlated Effects Mean Group estimator and Augmented Mean Group estimator was developed in Eberhardt and Teal (2010).

\section{Appendix Table 1: Granger Causality Test for China}

\begin{tabular}{lcc}
\hline Null Hypotheses & $\chi^{2}$ & Probability \\
\hline RV does not Granger causes GGDP & 8.342 & 0.065 \\
INF does not Granger causes GGDP & 6.638 & 0.084 \\
GGDP does not Granger causes RV & 8.838 & 0.052 \\
INF does not Granger causes RV & 3.894 & 0.273 \\
GGDP does not Granger causes INF & 31.697 & 0.000 \\
RV does not Granger causes INF & 0.618 & 0.892 \\
\hline
\end{tabular}

Note: Here RV is dependent variable.

Appendix Table 2: Bayesian VAR Estimates for China

\begin{tabular}{cccc}
\hline & GGDP & RV & INF \\
\hline GGDP(-1) & -4.065791 & -0.001563 & 7.027548 \\
& {$[-2.80730]$} & {$[-0.92727]$} & {$[4.50008]$} \\
GGDP(-2) & -3.025617 & -0.000355 & 6.018085 \\
& {$[-2.54358]$} & {$[-0.36539]$} & {$[3.56899]$} \\
RV(-1) & 1.555661 & 0.222277 & -7.481045 \\
& {$[0.41503]$} & {$[2.82941]$} & {$[-2.93255]$} \\
RV(-2) & 0.403624 & 0.011923 & -1.379334 \\
& {$[0.18053]$} & {$[0.25376]$} & {$[-0.90655]$} \\
INF(-1) & -0.051392 & $1.62 \mathrm{E}-05$ & 0.617725 \\
& {$[-0.61143]$} & {$[0.00923]$} & {$[10.7411]$} \\
INF(-2) & -0.025009 & 0.001682 & 0.040673 \\
& {$[-0.39506]$} & {$[1.27593]$} & {$[0.93615]$} \\
$\mathrm{C}$ & 4.808395 & 0.028562 & 0.955795 \\
& {$[9.15165]$} & {$[2.62134]$} & {$[2.68574]$} \\
$\mathrm{R}{ }^{2}$ & 0.65697 & 0.773962 & 0.766630 \\
\hline
\end{tabular}

Note: Litterman/Minnesota prior type used with hyper parameter Mu: 0, L1: 0.1, L2: 0.99, L3: 1. T-statistics are provided in the parenthesis.

Appendix Table 3: Findings from Generalized Forecast Error Variance Decomposition for China Quarters Variance Decomposition Variance Decomposition Variance Decomposition of 


\begin{tabular}{cccccccccc}
\hline & \multicolumn{3}{c}{ of GGDP } & \multicolumn{3}{c}{ of RV } & \multicolumn{3}{c}{ INF } \\
\cline { 2 - 10 } & GGDP & RV & INF & GGDP & RV & INF & GGDP & RV & INF \\
\hline 1 & 0.829 & 0.178 & 0.154 & 0.270 & 0.875 & 0.012 & 0.224 & 0.154 & 0.733 \\
5 & 0.693 & 0.171 & 0.225 & 0.255 & 0.852 & 0.077 & 0.289 & 0.141 & 0.613 \\
10 & 0.624 & 0.201 & 0.259 & 0.202 & 0.677 & 0.149 & 0.298 & 0.148 & 0.603 \\
15 & 0.579 & 0.205 & 0.284 & 0.179 & 0.633 & 0.106 & 0.297 & 0.148 & 0.603 \\
20 & 0.551 & 0.209 & 0.299 & 0.168 & 0.609 & 0.135 & 0.297 & 0.148 & 0.603 \\
\hline
\end{tabular}

Note: All the figures are estimates rounded to three decimal places. 500 Monte Carlo reputations were used. 500 Monte Carlo repetitions were implemented.

Appendix Table 4: Granger Causality Test for India

\begin{tabular}{lcc}
\hline Null Hypotheses & $\chi^{2}$ & Probability \\
\hline RV does not Granger causes GGDP & 4.3341 & 0.098 \\
INF does not Granger causes GGDP & 5.107 & 0.093 \\
GGDP does not Granger causes RV & 4.095 & 0.088 \\
INF does not Granger causes RV & 2.851 & 0.091 \\
GGDP does not Granger causes INF & 6.976 & 0.031 \\
RV does not Granger causes INF & 11.091 & 0.004 \\
\hline
\end{tabular}

Note: Here RV is dependent variable.

Appendix Table 5: Bayesian VAR Estimates for India

\begin{tabular}{cccc}
\hline & GGDP & RV & INF \\
\hline GGDP(-1) & -0.216400 & 0.000538 & -0.007516 \\
& {$[-3.64201]$} & {$[0.59640]$} & {$[-0.11977]$} \\
GGDP(-2) & -0.135036 & $3.69 \mathrm{E}-05$ & -0.004193 \\
& {$[-3.28632]$} & {$[0.05932]$} & {$[-0.09690]$} \\
GGDP(-3) & -0.062370 & -0.000131 & -0.001345 \\
& {$[-2.05939]$} & {$[-0.28669]$} & {$[-0.04223]$} \\
RV(-1) & -0.248246 & 0.231887 & -0.012797 \\
& {$[-4.05056]$} & {$[3.08218]$} & {$[-0.00246]$} \\
RV(-2) & -1.050176 & 0.010831 & 0.952198 \\
& {$[-2.34912]$} & {$[0.23429]$} & {$[5.61204]$} \\
RV(-3) & -0.395685 & -0.002200 & 1.068456 \\
& {$[-0.18986]$} & {$[-0.06865]$} & {$[6.48349]$} \\
INF(-1) & -0.003042 & 0.000903 & 0.550382 \\
& {$[-0.05225]$} & {$[1.01808]$} & {$[8.86903]$} \\
INF(-2) & -0.004958 & -0.000181 & 0.061453 \\
& {$[-0.11858]$} & {$[-0.28402]$} & {$[1.37406]$} \\
INF(-3) & 0.001458 & -0.000158 & 0.011573 \\
& {$[0.05026]$} & {$[-0.35775]$} & {$[0.37300]$} \\
C & 3.066624 & 0.020994 & 2.633360 \\
& {$[6.00197]$} & {$[2.69848]$} & {$[4.85780]$} \\
& & & \\
R ${ }^{2}$ & 0.615809 & 0.621730 & 0.657550
\end{tabular}

Note: Litterman/Minnesota prior type used with hyper parameter Mu: 0, L1: 0.1, L2: 0.99, L3: 1. T-statistics are provided in the parenthesis.

Appendix Table 6: Findings from Generalized Forecast Error Variance Decomposition for India

\begin{tabular}{|c|c|c|c|c|c|c|c|c|c|}
\hline \multirow[t]{2}{*}{ Quarters } & \multicolumn{3}{|c|}{$\begin{array}{c}\text { Variance Decomposition } \\
\text { of GGDP }\end{array}$} & \multicolumn{3}{|c|}{$\begin{array}{c}\text { Variance Decomposition } \\
\text { of RV }\end{array}$} & \multicolumn{3}{|c|}{$\begin{array}{c}\text { Variance Decomposition of } \\
\text { INF }\end{array}$} \\
\hline & GGDP & RV & INF & GGDP & RV & INF & GGDP & RV & INF \\
\hline
\end{tabular}




\begin{tabular}{llllllllll}
\hline 1 & 0.913 & 0.054 & 0.109 & 0.046 & 0.971 & 0.139 & 0.169 & 0.079 & 0.825 \\
5 & 0.716 & 0.182 & 0.205 & 0.123 & 0.832 & 0.169 & 0.169 & 0.226 & 0.652 \\
10 & 0.617 & 0.235 & 0.251 & 0.117 & 0.810 & 0.191 & 0.161 & 0.274 & 0.618 \\
15 & 0.571 & 0.261 & 0.272 & 0.114 & 0.806 & 0.196 & 0.157 & 0.295 & 0.604 \\
20 & 0.546 & 0.274 & 0.283 & 0.113 & 0.804 & 0.199 & 0.155 & 0.306 & 0.597 \\
\hline
\end{tabular}

Note: All the figures are estimates rounded to three decimal places. 500 Monte Carlo reputations were used. 500 Monte Carlo repetitions were implemented.

Appendix Table 7: Granger Causality Test for Indonesia from 1993:2 to 2013:4

\begin{tabular}{lcc}
\hline Null Hypotheses & $\chi^{2}$ & Probability \\
\hline RV does not Granger causes GGDP & 33.306 & 0.000 \\
INF does not Granger causes GGDP & 6.736 & 0.097 \\
GGDP does not Granger causes RV & 5.076 & 0.279 \\
INF does not Granger causes RV & 7.383 & 0.066 \\
GGDP does not Granger causes INF & 9.141 & 0.015 \\
RV does not Granger causes INF & 13.105 & 0.011 \\
\hline
\end{tabular}

Note: Here RV is dependent variable.

Appendix Table 8: Bayesian VAR Estimates for Indonesia from 1993:2 to 2013:4

\begin{tabular}{cccc}
\hline & GGDP & RV & \multicolumn{1}{c}{ INF } \\
\hline GGDP(-1) & 0.034514 & -0.004278 & -0.649043 \\
& {$[0.44041]$} & {$[-1.45759]$} & {$[-4.20076]$} \\
GGDP(-2) & -0.016495 & 0.000407 & -0.204991 \\
& {$[-0.35224]$} & {$[0.23259]$} & {$[-2.22623]$} \\
RV(-1) & -5.007620 & 0.174866 & 14.46214 \\
& {$[-2.51753]$} & {$[2.32061]$} & {$[3.66632]$} \\
RV(-2) & -0.321644 & 0.003992 & 5.107086 \\
& {$[-5.26379]$} & {$[0.08616]$} & {$[2.11164]$} \\
INF(-1) & -0.020116 & 0.000684 & 0.767375 \\
& {$[-0.84656]$} & {$[0.76422]$} & {$[16.2052]$} \\
INF(-2) & 0.013658 & -0.000272 & -0.092745 \\
& {$[0.69894]$} & {$[-0.36933]$} & {$[-12.37578]$} \\
C & 1.407801 & 0.039337 & 3.601403 \\
& {$[4.04165]$} & {$[3.00123]$} & {$[5.21960]$} \\
$\mathrm{R}^{2}$ & 0.585607 & 0.678397 & 0.892766
\end{tabular}

Note: Litterman/Minnesota prior type used with hyper parameter Mu: 0, L1: 0.1, L2: 0.99, L3: 1. T-statistics are provided in the parenthesis.

Appendix Table 9: Findings from Generalized Forecast Error Variance Decomposition for Indonesia from 1993:2 to 2013:4

\begin{tabular}{lccccccccc}
\hline $\begin{array}{c}\text { Qua } \\
\text { rters }\end{array}$ & \multicolumn{3}{c}{$\begin{array}{c}\text { Variance Decomposition } \\
\text { of GGDP }\end{array}$} & \multicolumn{3}{c}{$\begin{array}{c}\text { Variance Decomposition } \\
\text { of RV }\end{array}$} & \multicolumn{2}{c}{ Variance Decomposition of INF } \\
\cline { 2 - 10 } & GGDP & RV & INF & GGDP & RV & INF & GGDP & RV & INF \\
\hline 1 & 0.641 & 0.618 & 0.319 & 0.149 & 0.987 & 0.254 & 0.244 & 0.761 & 0.847 \\
5 & 0.529 & 0.679 & 0.350 & 0.124 & 0.956 & 0.227 & 0.223 & 0.804 & 0.686 \\
10 & 0.532 & 0.664 & 0.344 & 0.123 & 0.943 & 0.216 & 0.221 & 0.791 & 0.671
\end{tabular}



repetitions were implemented.

Appendix Table 10: Granger Causality Test for Indonesia from 1998:4 to 2013:4

\begin{tabular}{lcc}
\hline Null Hypotheses & $\chi^{2}$ & Probability \\
\hline RV does not Granger causes GGDP & 54.799 & 0.000 \\
INF does not Granger causes GGDP & 4.265 & 0.087 \\
GGDP does not Granger causes RV & 1.237 & 0.872 \\
INF does not Granger causes RV & 1.031 & 0.905 \\
GGDP does not Granger causes INF & 7.237 & 0.047 \\
RV does not Granger causes INF & 3.031 & 0.091 \\
\hline
\end{tabular}

Note: Here RV is dependent variable.

Appendix Table 11: Bayesian VAR Estimates for Indonesia from 1998:4 to 2013:4

\begin{tabular}{|c|c|c|c|}
\hline & GGDP & RV & INF \\
\hline \multirow[t]{2}{*}{ GGDP(-1) } & -0.162352 & -0.008682 & -0.066929 \\
\hline & {$[-2.30135]$} & {$[-1.81200]$} & {$[-3.42819]$} \\
\hline \multirow[t]{2}{*}{$\operatorname{GGDP}(-2)$} & -0.074445 & 0.000992 & -0.013181 \\
\hline & {$[-1.65329]$} & [ 0.32543$]$ & {$[-0.13253]$} \\
\hline \multirow{2}{*}{$\operatorname{GGDP}(-3)$} & -0.022796 & 0.000125 & -0.001301 \\
\hline & {$[-0.72298]$} & [0.05875] & {$[-3.01869]$} \\
\hline \multirow[t]{2}{*}{ GGDP(-4) } & 0.038299 & $9.46 \mathrm{E}-06$ & 0.002265 \\
\hline & [ 1.58896$]$ & {$[0.00580]$} & [ 0.04259] \\
\hline \multirow[t]{2}{*}{$\mathrm{RV}(-1)$} & -0.301835 & 0.062427 & -1.604498 \\
\hline & {$[-6.25552]$} & [ 0.76901$]$ & {$[-0.60995]$} \\
\hline \multirow[t]{2}{*}{$\mathrm{RV}(-2)$} & -0.265322 & 0.007106 & -0.900986 \\
\hline & {$[-0.38861]$} & [0.15110] & {$[-0.59257]$} \\
\hline \multirow{2}{*}{$\mathrm{RV}(-3)$} & -0.246975 & 0.001208 & -0.288435 \\
\hline & {$[-2.52520]$} & [0.03726] & {$[-0.27542]$} \\
\hline \multirow[t]{2}{*}{$\mathrm{RV}(-4)$} & -0.002643 & -0.003480 & -0.083653 \\
\hline & {$[-0.00740]$} & {$[-0.14138]$} & {$[-0.10522]$} \\
\hline \multirow[t]{2}{*}{$\operatorname{INF}(-1)$} & -0.019128 & 0.001406 & 0.504821 \\
\hline & {$[-0.67965]$} & [ 0.73174$]$ & [ 8.01354] \\
\hline \multirow[t]{2}{*}{$\operatorname{INF}(-2)$} & -0.005450 & 0.000333 & 0.035493 \\
\hline & {$[-0.28462]$} & [ 0.25494] & [ 0.82528$]$ \\
\hline \multirow[t]{2}{*}{$\operatorname{INF}(-3)$} & 0.003794 & -0.000206 & -0.030926 \\
\hline & [ 0.30088] & {$[-0.23942]$} & [-1.09187] \\
\hline \multirow[t]{2}{*}{$\operatorname{INF}(-4)$} & 0.003061 & $-6.94 \mathrm{E}-05$ & -0.046647 \\
\hline & [ 0.35148$]$ & {$[-0.11673]$} & [-2.38677] \\
\hline \multirow[t]{2}{*}{$\mathrm{C}$} & 1.772295 & 0.034331 & 4.405804 \\
\hline & [ 5.86816] & [ 1.66783] & [ 6.55126] \\
\hline $\mathrm{R}^{2}$ & 0.593864 & 0.730849 & 0.934435 \\
\hline
\end{tabular}

Note: Litterman/Minnesota prior type used with hyper parameter Mu: 0, L1: 0.1, L2: 0.99, L3: 1. T-statistics are provided in the parenthesis.

Appendix Table 12: Findings from Generalized Forecast Error Variance Decomposition for Indonesia from 1998:4 to 2013:3

\begin{tabular}{|c|c|c|c|c|c|c|c|c|c|}
\hline \multirow[t]{2}{*}{$\begin{array}{l}\text { Quarter } \\
\text { s }\end{array}$} & \multicolumn{3}{|c|}{$\begin{array}{c}\text { Variance Decomposition } \\
\text { of GGDP }\end{array}$} & \multicolumn{3}{|c|}{$\begin{array}{c}\text { Variance Decomposition of } \\
\text { RV }\end{array}$} & \multicolumn{3}{|c|}{$\begin{array}{c}\text { Variance Decomposition of } \\
\text { INF }\end{array}$} \\
\hline & GGDP & RV & INF & GGDP & $\mathrm{RV}$ & INF & $\begin{array}{l}\text { GGD } \\
\mathrm{P}\end{array}$ & $\mathrm{RV}$ & INF \\
\hline 1 & 0.879 & 0.114 & 0.055 & 0.053 & 0.939 & 0.020 & 0.154 & 0.149 & 0.846 \\
\hline 5 & 0.784 & 0.124 & 0.177 & 0.095 & 0.893 & 0.029 & 0.227 & 0.192 & 0.735 \\
\hline 10 & 0.754 & 0.154 & 0.180 & 0.172 & 0.802 & 0.064 & 0.264 & 0.225 & 0.671 \\
\hline 15 & 0.737 & 0.172 & 0.181 & 0.106 & 0.862 & 0.082 & 0.285 & 0.244 & 0.634 \\
\hline 20 & 0.728 & 0.182 & 0.181 & 0.122 & 0.841 & 0.091 & 0.296 & 0.255 & 0.613 \\
\hline
\end{tabular}


Note: All the figures are estimates rounded to three decimal places. 500 Monte Carlo reputations were used

Appendix Table 13: Granger Causality Test for Malaysia from 1991:2 to 2013:3

\begin{tabular}{lcc}
\hline Null Hypotheses & $\chi^{2}$ & Probability \\
\hline RV does not Granger causes GGDP & 4.957 & 0.084 \\
INF does not Granger causes GGDP & 4.077 & 0.096 \\
GGDP does not Granger causes RV & 4.625 & 0.099 \\
INF does not Granger causes RV & 7.765 & 0.021 \\
GGDP does not Granger causes INF & 7.721 & 0.006 \\
RV does not Granger causes INF & 3.013 & 0.222 \\
\hline
\end{tabular}

Note: Here RV is dependent variable.

Appendix Table 14: Bayesian VAR Estimates for Malaysia

\begin{tabular}{llll}
\hline & GGDP & RV & INF \\
\hline GGDP(-1) & 0.086477 & -0.002941 & -0.029028 \\
& {$[1.17332]$} & {$[-1.29353]$} & {$[-0.55151]$} \\
GGDP(-2) & -0.030480 & -0.000380 & 0.035317 \\
& {$[-0.67521]$} & {$[-0.27379]$} & {$[4.09880]$} \\
RV(-1) & -0.271398 & $3.13 \mathrm{E}-05$ & -0.628620 \\
& {$[-7.11265]$} & {$[0.00042]$} & {$[-0.36350]$} \\
RV(-2) & -0.269948 & 0.002268 & -1.140844 \\
& {$[-30.18553]$} & {$[0.04983]$} & {$[-1.09230]$} \\
INF(-1) & -0.061106 & 0.005246 & 0.190029 \\
& {$[-2.59753]$} & {$[1.65433]$} & {$[2.57492]$} \\
INF(-2) & -0.000332 & 0.003522 & -0.001746 \\
& {$[-0.00528]$} & {$[1.80349]$} & {$[-0.03832]$} \\
C & 1.335637 & 0.027937 & 0.926057 \\
& {$[4.35163]$} & {$[2.93745]$} & {$[4.20572]$} \\
R $^{2}$ & 0.543610 & 0.681267 & 0.960559
\end{tabular}

Note: Litterman/Minnesota prior type used with hyper parameter Mu: 0, L1: 0.1, L2: 0.99, L3: 1. T-statistics are provided in the parenthesis.

Appendix Table 15: Findings from Generalized Forecast Error Variance Decomposition for Malaysia from 1991:2 to 2013:3

\begin{tabular}{lccccccccc}
\hline Quarters & \multicolumn{3}{c}{$\begin{array}{c}\text { Variance Decomposition } \\
\text { of GGDP }\end{array}$} & \multicolumn{3}{c}{$\begin{array}{c}\text { Variance Decomposition } \\
\text { of RV }\end{array}$} & \multicolumn{3}{c}{$\begin{array}{c}\text { Variance Decomposition of } \\
\text { INF }\end{array}$} \\
\cline { 2 - 11 } & GGDP & RV & INF & GGDP & RV & INF & GGDP & RV & INF \\
\hline 1 & 0.896 & 0.135 & 0.122 & 0.094 & 0.945 & 0.247 & 0.320 & 0.019 & 0.966 \\
5 & 0.810 & 0.222 & 0.165 & 0.169 & 0.845 & 0.189 & 0.275 & 0.142 & 0.747 \\
10 & 0.749 & 0.242 & 0.184 & 0.169 & 0.802 & 0.176 & 0.297 & 0.161 & 0.652 \\
15 & 0.712 & 0.261 & 0.190 & 0.171 & 0.783 & 0.172 & 0.319 & 0.160 & 0.608 \\
20 & 0.690 & 0.273 & 0.193 & 0.172 & 0.773 & 0.171 & 0.332 & 0.158 & 0.584 \\
\hline
\end{tabular}

Note: All the figures are estimates rounded to three decimal places. 500 Monte Carlo reputations were used. 500 Monte Carlo repetitions were implemented.

Appendix Table 16: Granger Causality Test for Malaysia from 1998:4 to 2013:3

\begin{tabular}{lcc}
\hline Null Hypotheses & $\chi^{2}$ & Probability \\
\hline RV does not Granger causes GGDP & 4.490 & 0.088 \\
INF does not Granger causes GGDP & 7.806 & 0.066 \\
GGDP does not Granger causes RV & 5.957 & 0.071 \\
INF does not Granger causes RV & 4.343 & 0.091 \\
GGDP does not Granger causes INF & 13.586 & 0.016 \\
RV does not Granger causes INF & 3.099 & 0.212 \\
\hline
\end{tabular}

Note: Here RV is dependent variable.

Appendix Table 17: Bayesian VAR Estimates for Malaysia from 1998:4 to 2013:3 


\begin{tabular}{lccc}
\hline & GGDP & RV & INF \\
\hline GGDP(-1) & 0.059027 & -0.004344 & -0.042481 \\
& {$[0.73960]$} & {$[-1.24423]$} & {$[-0.53746]$} \\
GGDP(-2) & -0.041131 & -0.000110 & 0.040782 \\
& {$[-0.88455]$} & {$[-0.05416]$} & {$[0.88780]$} \\
GGDP(-3) & -0.007934 & -0.000277 & 0.014618 \\
& {$[-0.24816]$} & {$[-0.19854]$} & {$[0.46307]$} \\
GGDP(-4) & 0.003932 & $5.09 E-05$ & -0.007750 \\
& {$[0.16114]$} & {$[0.04786]$} & {$[-0.32180]$} \\
RV(-1) & -0.842312 & -0.008926 & -0.618848 \\
& {$[-0.45490]$} & {$[-0.10879]$} & {$[-0.33541]$} \\
RV(-2) & -0.400436 & 0.000942 & -0.841638 \\
& {$[-2.37827]$} & {$[0.02005]$} & {$[-0.79786]$} \\
RV(-3) & -0.126929 & 0.000646 & -0.141066 \\
& {$[-0.17407]$} & {$[0.01992]$} & {$[-0.19413]$} \\
RV(-4) & -0.015181 & -0.001721 & 0.033145 \\
& {$[-0.02744]$} & {$[-0.06998]$} & {$[0.06013]$} \\
INF(-1) & -0.057192 & 0.004252 & 0.157585 \\
& {$[-0.71608]$} & {$[1.20972]$} & {$[1.96770]$} \\
INF(-2) & -0.005960 & 0.002611 & 0.002025 \\
& {$[-5.12782]$} & {$[1.27184]$} & {$[0.04320]$} \\
INF(-3) & -0.000500 & 0.000613 & -0.000201 \\
INF(-4) & {$[-3.01547]$} & {$[0.43080]$} & {$[-0.00617]$} \\
& 0.001144 & $1.94 \mathrm{E}-05$ & 0.003569 \\
C & {$[0.04672]$} & {$[0.01803]$} & {$[0.14487]$} \\
& 1.343493 & 0.034146 & 1.010803 \\
$R^{2}$ & {$[4.42865]$} & {$[2.55975]$} & {$[3.34618]$} \\
& 0.535987 & 0.609745 & 0.866070 \\
\hline
\end{tabular}

Note: Litterman/Minnesota prior type used with hyper parameter Mu: 0, L1: 0.1, L2: 0.99, L3: 1. T-statistics are provided in the parenthesis.

Appendix Table 18: Findings from Generalized Forecast Error Variance Decomposition for Malaysia from 1998:4 to 2013:3

\begin{tabular}{|c|c|c|c|c|c|c|c|c|c|}
\hline \multirow[t]{2}{*}{ Quarters } & \multicolumn{3}{|c|}{$\begin{array}{c}\text { Variance Decomposition } \\
\text { of GGDP }\end{array}$} & \multicolumn{3}{|c|}{$\begin{array}{c}\text { Variance Decomposition } \\
\text { of RV }\end{array}$} & \multicolumn{3}{|c|}{$\begin{array}{l}\text { Variance Decomposition of } \\
\text { INF }\end{array}$} \\
\hline & GGDP & $\mathrm{RV}$ & INF & GGDP & $\mathrm{RV}$ & INF & GGDP & RV & INF \\
\hline 1 & 0.870 & 0.140 & 0.045 & 0.096 & 0.954 & 0.235 & 0.189 & 0.137 & 0.883 \\
\hline 5 & 0.818 & 0.205 & 0.153 & 0.134 & 0.859 & 0.137 & 0.237 & 0.271 & 0.847 \\
\hline 10 & 0.724 & 0.287 & 0.217 & 0.134 & 0.814 & 0.105 & 0.243 & 0.319 & 0.826 \\
\hline 15 & 0.687 & 0.308 & 0.201 & 0.133 & 0.797 & 0.095 & 0.243 & 0.330 & 0.776 \\
\hline 20 & 0.672 & 0.315 & 0.194 & 0.132 & 0.790 & 0.092 & 0.242 & 0.333 & 0.757 \\
\hline
\end{tabular}

Note: All the figures are estimates rounded to three decimal places. 500 Monte Carlo reputations were used. 500 Monte Carlo repetitions were implemented.

Appendix Table 19: Granger Causality Test for Philippines

\begin{tabular}{lcc}
\hline Null Hypotheses & $\chi^{2}$ & Probability \\
\hline RV does not Granger causes GGDP & 0.042 & 0.837 \\
INF does not Granger causes GGDP & 7.681 & 0.019 \\
GGDP does not Granger causes RV & 0.661 & 0.416 \\
INF does not Granger causes RV & 3.652 & 0.091 \\
GGDP does not Granger causes INF & 6.107 & 0.014 \\
RV does not Granger causes INF & 4.013 & 0.072 \\
\hline
\end{tabular}

Note: Here RV is dependent variable.

Appendix Table 20: Bayesian VAR Estimates for Philippines

\begin{tabular}{cccc}
\hline & GGDP & RV & \multicolumn{1}{c}{ INF } \\
\hline GGDP(-1) & -0.101637 & 0.000205 & -0.004600 \\
& {$[-1.57991]$} & {$[0.15172]$} & {$[-0.10574]$} \\
GGDP(-2) & -0.133297 & -0.000717 & 0.005596
\end{tabular}




$\begin{array}{cccc} & {[-3.10284]} & {[-0.79658]} & {[5.19327]} \\ \operatorname{RV}(-1) & -1.902061 & 0.172632 & 0.137039 \\ & {[-0.58112]} & {[2.48484]} & {[0.06165]} \\ \operatorname{RV}(-2) & -2.792260 & 0.026812 & -0.672931 \\ & {[-1.35413]} & {[0.61082]} & {[-0.48057]} \\ \operatorname{INF}(-1) & -0.049707 & 0.003782 & 0.474218 \\ & {[-0.56564]} & {[2.03710]} & {[7.91146]} \\ \mathrm{INF}(-2) & -0.038301 & 0.000447 & 0.033154 \\ & {[-0.61093]} & {[0.33756]} & {[0.77273]} \\ \mathrm{C} & 1.630947 & 0.021023 & 1.170319 \\ & {[5.25630]} & {[3.20786]} & {[5.55247]} \\ \mathrm{R}^{2} & 0.673041 & 0.777880 & 0.865006\end{array}$

Note: Litterman/Minnesota prior type used with hyper parameter Mu: 0, L1: 0.1, L2: 0.99, L3: 1. T-statistics are provided in the parenthesis.

Appendix Table 21: Findings from Generalized Forecast Error Variance Decomposition for Philippines

\begin{tabular}{|c|c|c|c|c|c|c|c|c|c|}
\hline \multirow[t]{2}{*}{ Quarters } & \multicolumn{3}{|c|}{$\begin{array}{c}\text { Variance Decomposition } \\
\text { of GGDP }\end{array}$} & \multicolumn{3}{|c|}{$\begin{array}{c}\text { Variance Decomposition } \\
\text { of RV }\end{array}$} & \multicolumn{3}{|c|}{$\begin{array}{c}\text { Variance Decomposition of } \\
\text { INF }\end{array}$} \\
\hline & GGDP & RV & INF & GGDP & RV & INF & GGDP & RV & INF \\
\hline 1 & 0.949 & 0.022 & 0.080 & 0.001 & 0.944 & 0.366 & 0.279 & 0.122 & 0.898 \\
\hline 5 & 0.841 & 0.061 & 0.189 & 0.006 & 0.841 & 0.481 & 0.296 & 0.227 & 0.795 \\
\hline 10 & 0.824 & 0.067 & 0.206 & 0.007 & 0.826 & 0.496 & 0.298 & 0.227 & 0.795 \\
\hline 15 & 0.823 & 0.067 & 0.208 & 0.007 & 0.825 & 0.497 & 0.298 & 0.227 & 0.795 \\
\hline 20 & 0.823 & 0.068 & 0.208 & 0.007 & 0.825 & 0.497 & 0.298 & 0.227 & 0.795 \\
\hline
\end{tabular}

Note: All the figures are estimates rounded to three decimal places. 500 Monte Carlo reputations were used. 500 Monte Carlo repetitions were implemented.

Appendix Table 22: Granger Causality Test for Thailand from 1993:2 to 2013:3

\begin{tabular}{lcc}
\hline Null Hypotheses & $\chi^{2}$ & Probability \\
\hline RV does not Granger causes GGDP & 17.945 & 0.000 \\
INF does not Granger causes GGDP & 11.701 & 0.001 \\
GGDP does not Granger causes RV & 0.009 & 0.924 \\
INF does not Granger causes RV & 6.694 & 0.009 \\
GGDP does not Granger causes INF & 0.318 & 0.573 \\
RV does not Granger causes INF & 0.152 & 0.696
\end{tabular}

Note: Here RV is dependent variable.

Appendix Table 23: Bayesian VAR Estimates for Thailand from 1993:2 to 2013:3

\begin{tabular}{llll}
\hline & GGDP & RV & INF \\
\hline GGDP(-1) & -0.062981 & -0.000862 & -0.004031 \\
& {$[-0.82957]$} & {$[-1.28801]$} & {$[-0.13522]$} \\
GGDP(-2) & -0.011764 & -0.000251 & 0.014704 \\
& {$[-0.25627]$} & {$[-0.62228]$} & {$[0.81803]$} \\
RV(-1) & -13.15033 & 0.250750 & -7.350609 \\
& {$[-1.63254]$} & {$[3.49329]$} & {$[-2.31093]$} \\
RV(-2) & 0.046025 & 0.028020 & -2.414874 \\
& {$[0.00904]$} & {$[0.61560]$} & {$[-1.20101]$} \\
INF(-1) & -0.305901 & 0.001425 & 0.390537 \\
INF(-2) & {$[-1.84917]$} & {$[0.97151]$} & {$[5.94880]$} \\
& -0.065756 & 0.001613 & 0.008692 \\
$\mathrm{C}$ & {$[-0.59005]$} & {$[1.63312]$} & {$[0.19589]$} \\
& 1.974302 & 0.020392 & 1.155401 \\
$\mathrm{R}^{2}$ & {$[3.67642]$} & {$[4.27799]$} & {$[5.44633]$} \\
\hline
\end{tabular}

Note: Litterman/Minnesota prior type used with hyper parameter Mu: 0, L1: 0.1, L2: 0.99, L3: 1. T-statistics are provided in the parenthesis.

Appendix Table 24: Findings from Generalized Forecast Error Variance Decomposition for Thailand from 1993:2 to 2013:3

Quarters Variance Decomposition Variance Decomposition Variance Decomposition of 


\begin{tabular}{lccccccccc}
\hline & \multicolumn{3}{c}{ of GGDP } & \multicolumn{3}{c}{ of RV } & \multicolumn{3}{c}{ INF } \\
\cline { 2 - 9 } & GGDP & RV & INF & GGDP & RV & INF & GGDP & RV & INF \\
\hline 1 & 0.969 & 0.045 & 0.051 & 0.037 & 0.947 & 0.053 & 0.021 & 0.030 & 0.961 \\
5 & 0.894 & 0.152 & 0.104 & 0.046 & 0.786 & 0.213 & 0.058 & 0.044 & 0.834 \\
10 & 0.891 & 0.154 & 0.106 & 0.055 & 0.735 & 0.261 & 0.065 & 0.088 & 0.789 \\
15 & 0.889 & 0.154 & 0.106 & 0.057 & 0.721 & 0.273 & 0.066 & 0.101 & 0.776 \\
20 & 0.889 & 0.155 & 0.107 & 0.058 & 0.717 & 0.276 & 0.067 & 0.105 & 0.772 \\
\hline
\end{tabular}

Note: All the figures are estimates rounded to three decimal places. 500 Monte Carlo reputations were used. 500 Monte Carlo repetitions were implemented.

Table 25: Granger Causality Test for Thailand from 1998:4 to 2013:3

\begin{tabular}{lcc}
\hline Null Hypotheses & $\chi^{2}$ & Probability \\
\hline RV does not Granger causes GGDP & 3.774 & 0.152 \\
INF does not Granger causes GGDP & 5.609 & 0.074 \\
GGDP does not Granger causes RV & 1.568 & 0.114 \\
INF does not Granger causes RV & 0.446 & 0.800 \\
GGDP does not Granger causes INF & 17.655 & 0.000 \\
RV does not Granger causes INF & 4.159 & 0.125 \\
\hline
\end{tabular}

Note: Here RV is dependent variable.

Appendix Table 26: Bayesian VAR Estimates for Thailand from 1998:1 to 2013:3

\begin{tabular}{llcc}
\hline & GGDP & RV & INF \\
\hline GGDP(-1) & -0.122699 & -0.000674 & -0.002098 \\
& {$[-1.54489]$} & {$[-0.88269]$} & {$[-0.05644]$} \\
GGDP(-2) & -0.015799 & -0.000154 & 0.015796 \\
RV(-1) & {$[-0.33883]$} & {$[-0.34356]$} & {$[0.72542]$} \\
& -8.165248 & 0.237357 & -8.533456 \\
RV(-2) & {$[-1.04868]$} & {$[3.13472]$} & {$[-2.32641]$} \\
& 1.139720 & 0.016890 & -2.416204 \\
& $(4.75550)$ & $(0.04638)$ & $(2.24044)$ \\
INF(-1) & {$[0.23966]$} & {$[0.36416]$} & {$[-1.07845]$} \\
& -0.207193 & 0.001236 & 0.344899 \\
INF(-2) & {$[-1.39763]$} & {$[0.86217]$} & {$[4.91163]$} \\
& -0.074671 & 0.001303 & 0.016141 \\
C & {$[-0.78207]$} & {$[1.41149]$} & {$[0.35578]$} \\
& 1.927972 & 0.022002 & 1.244987 \\
$R^{2}$ & {$[3.55405]$} & {$[4.18896]$} & {$[4.87004]$} \\
& 0.69016428 & 0.7953171 & 0.9340562
\end{tabular}

Note: Litterman/Minnesota prior type used with hyper parameter Mu: 0, L1: 0.1, L2: 0.99, L3: 1. T-statistics are provided in the parenthesis. 


\begin{tabular}{lccccccccc}
\hline Quarters & \multicolumn{3}{c}{$\begin{array}{c}\text { Variance Decomposition } \\
\text { of GGDP }\end{array}$} & \multicolumn{3}{c}{$\begin{array}{c}\text { Variance Decomposition of } \\
\text { RV }\end{array}$} & \multicolumn{3}{c}{$\begin{array}{c}\text { Variance Decomposition } \\
\text { of INF }\end{array}$} \\
\cline { 2 - 10 } & GGDP & RV & INF & GGDP & RV & INF & GGDP & RV & INF \\
\hline 1 & 0.986 & 0.058 & 0.182 & 0.037 & 0.985 & 0.032 & 0.109 & 0.016 & 0.979 \\
5 & 0.867 & 0.069 & 0.301 & 0.118 & 0.945 & 0.114 & 0.203 & 0.060 & 0.885 \\
10 & 0.891 & 0.077 & 0.345 & 0.129 & 0.933 & 0.163 & 0.224 & 0.105 & 0.835 \\
15 & 0.863 & 0.078 & 0.361 & 0.103 & 0.944 & 0.180 & 0.233 & 0.124 & 0.813 \\
20 & 0.850 & 0.075 & 0.369 & 0.108 & 0.934 & 0.188 & 0.237 & 0.134 & 0.802 \\
\hline
\end{tabular}

Note: All the figures are estimates rounded to three decimal places. 500 Monte Carlo reputations were used. 500 Monte Carlo repetitions were implemented. 
Figure 1: Variables Used in This Paper

a. China

Decomposed RV

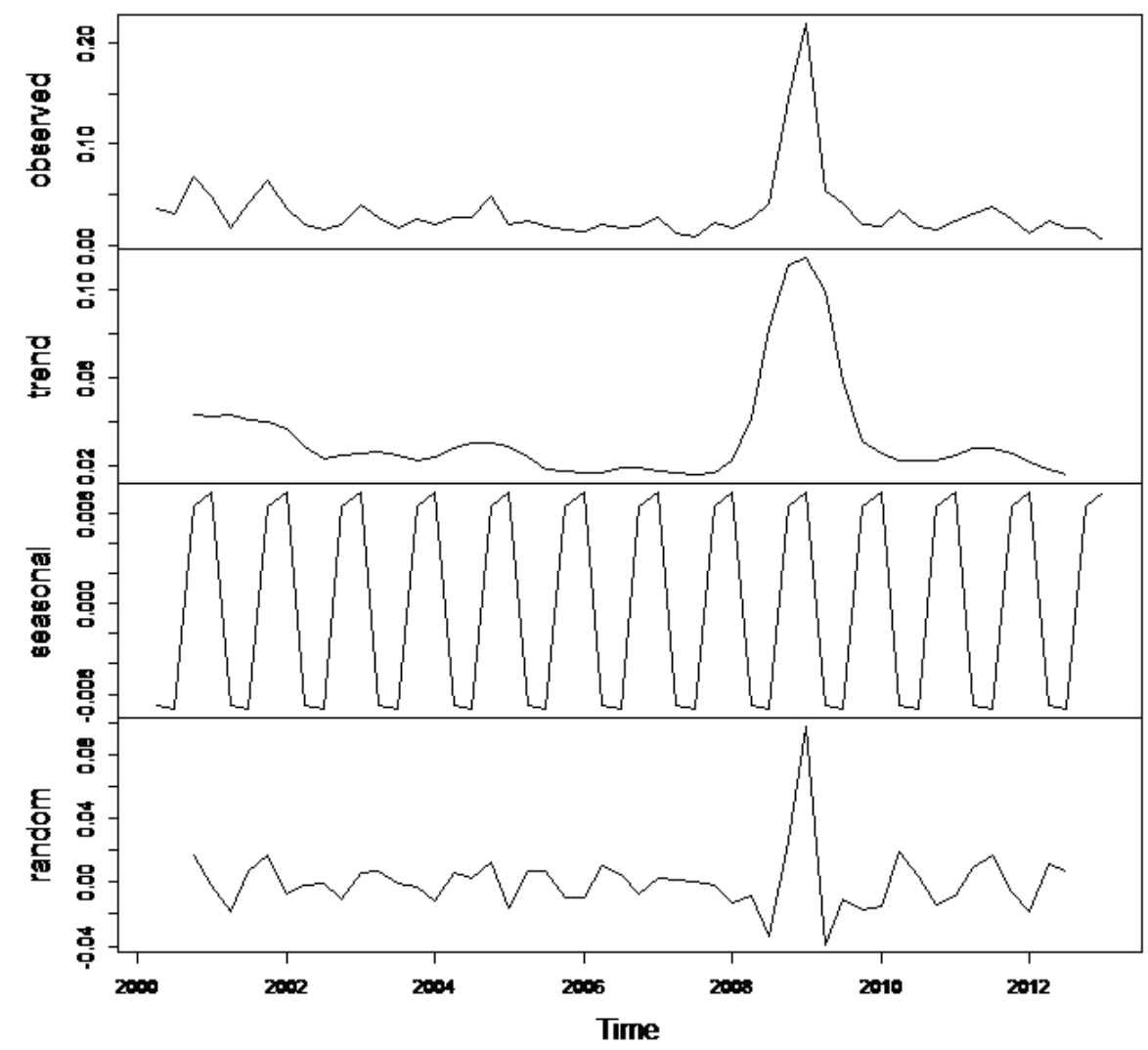

Decomposed GGDP

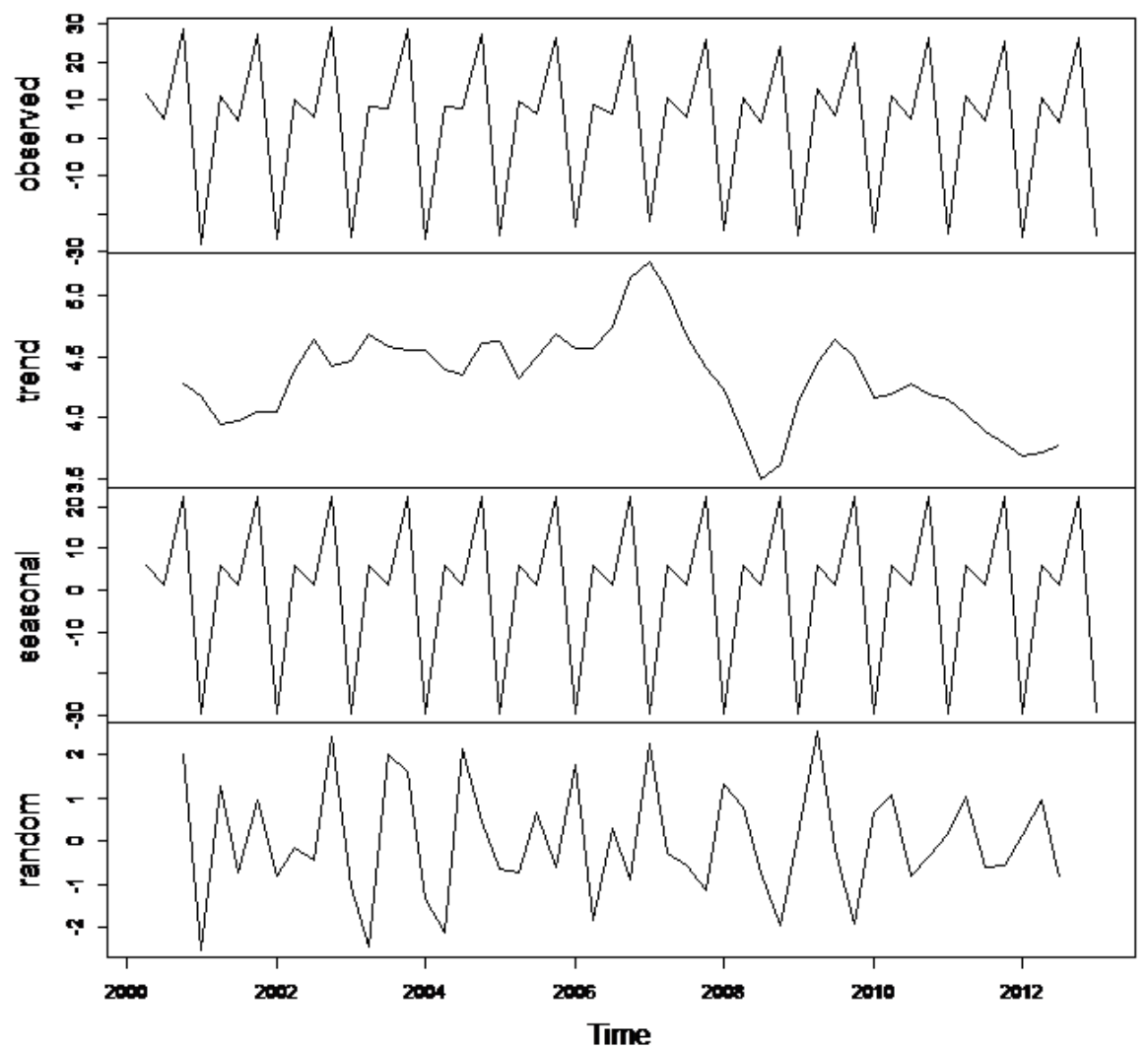

Decomposed INF 


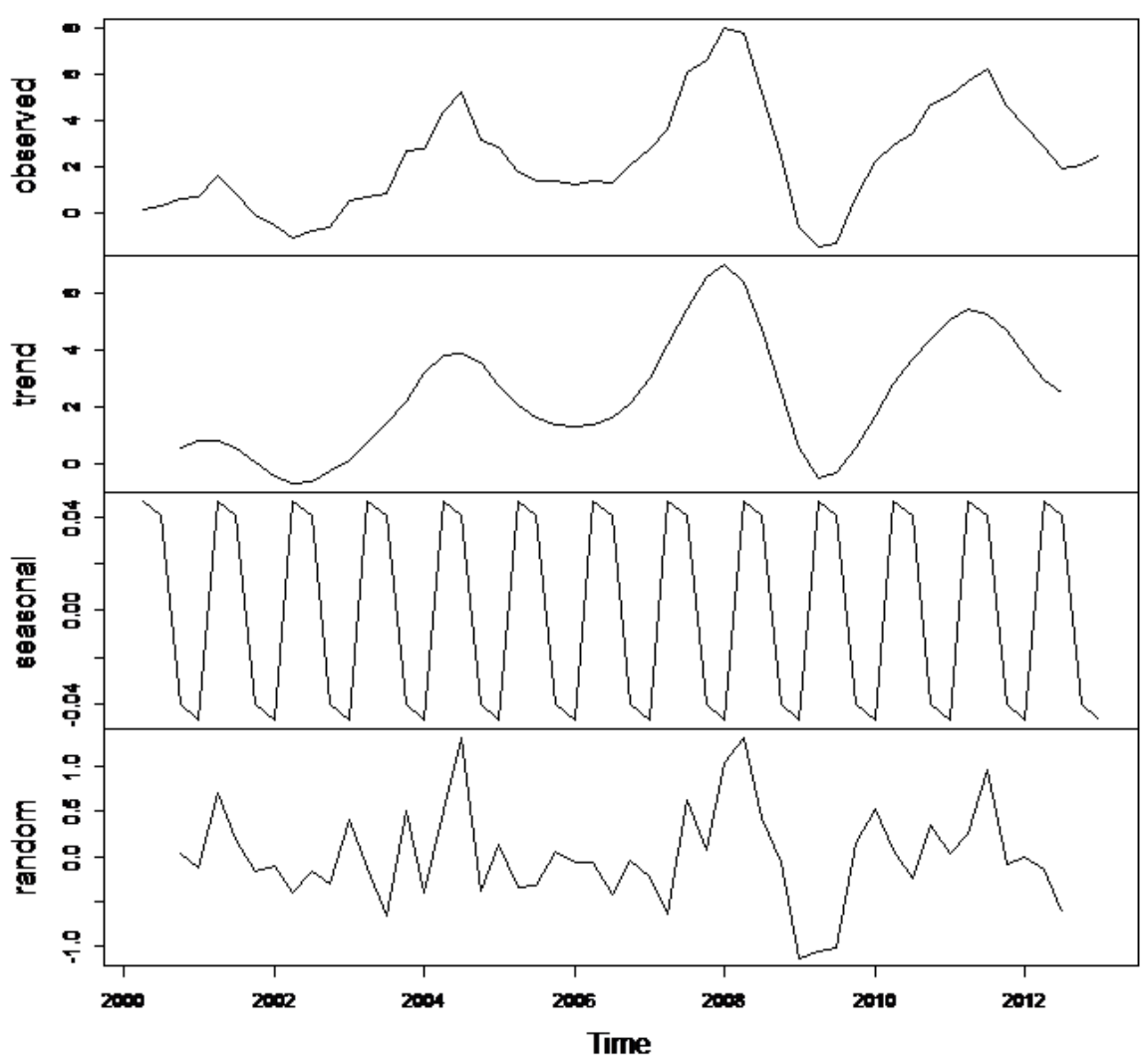

b. India

Decomposed RV

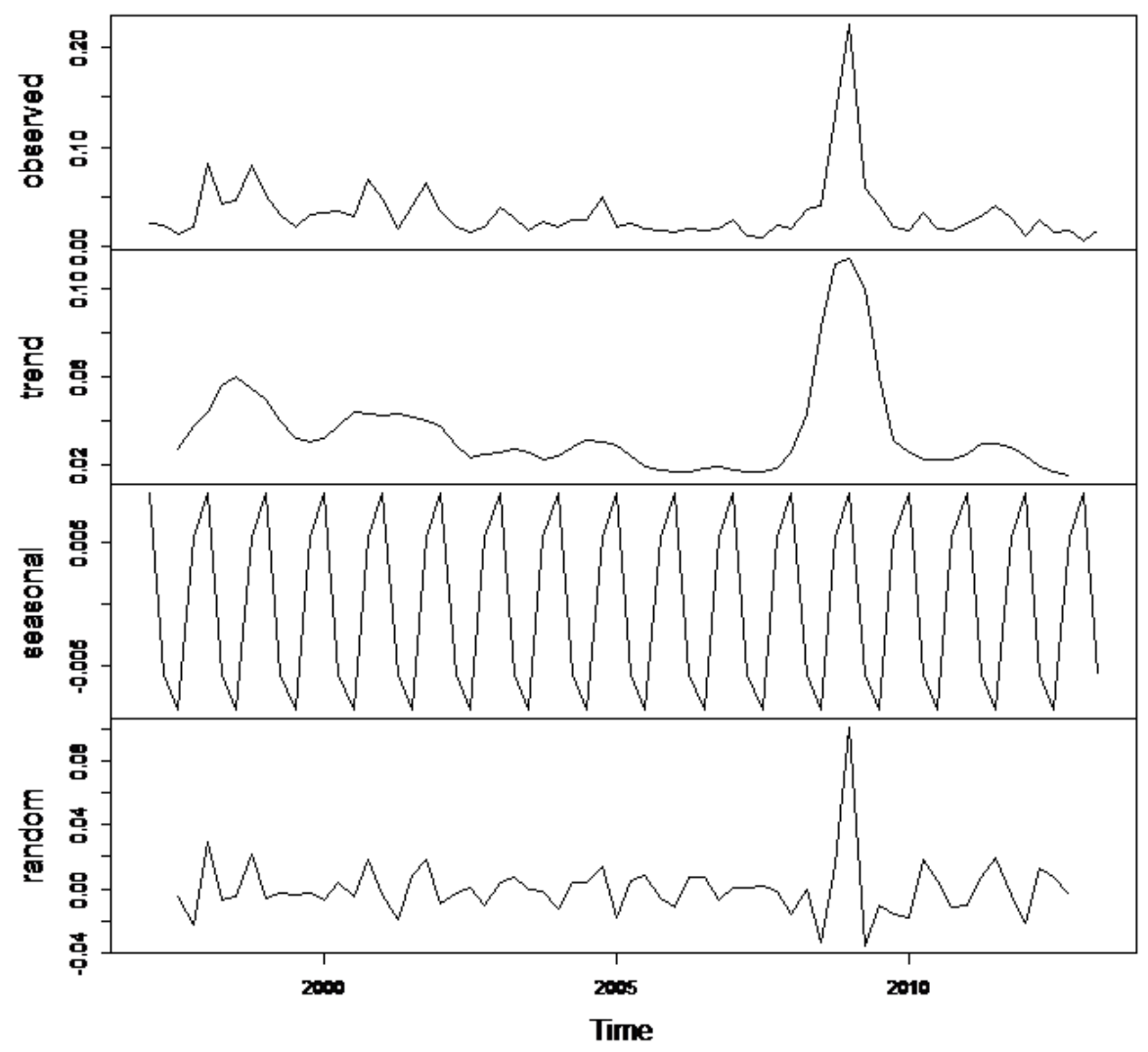

Decomposed GGDP 


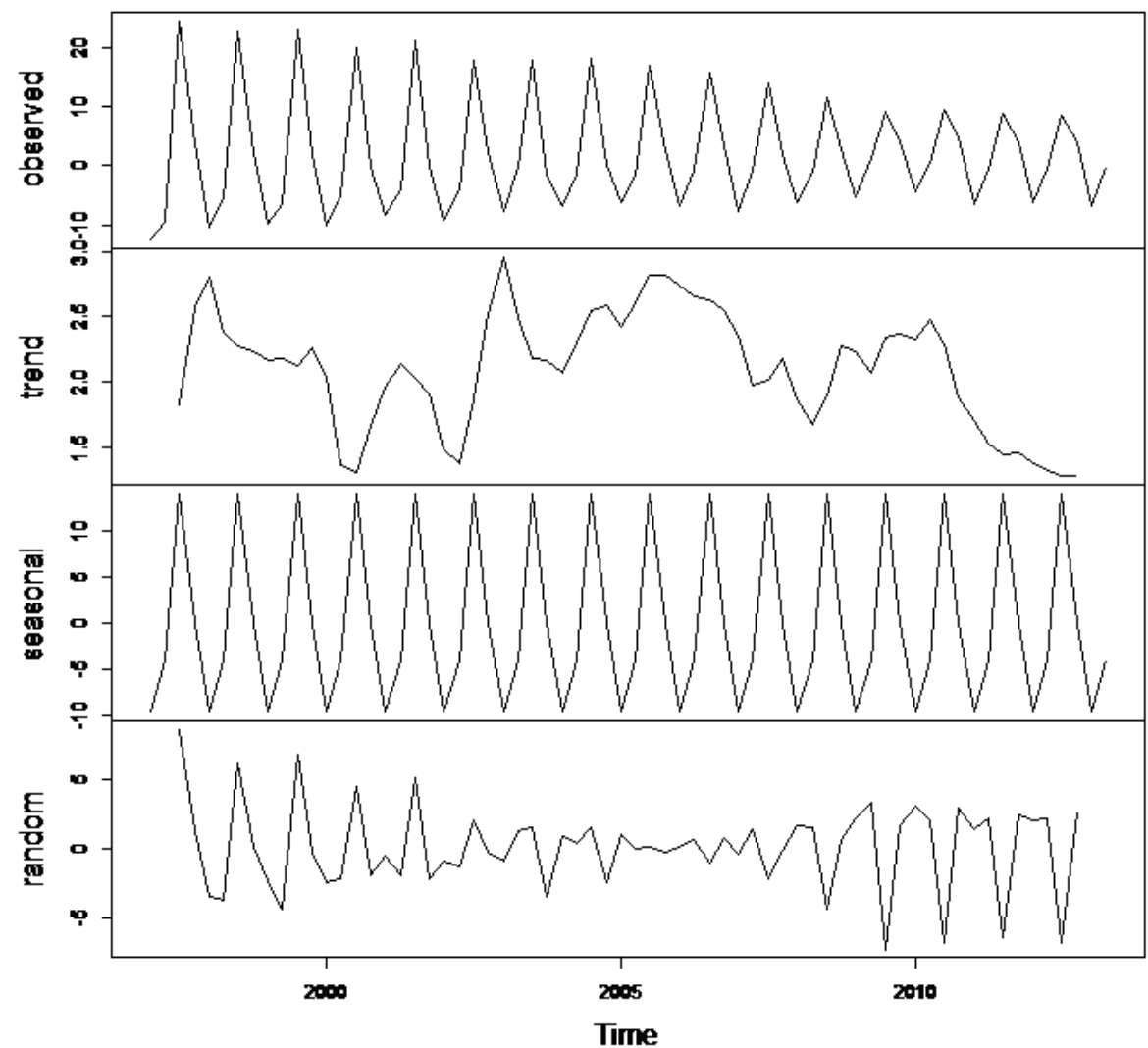

Decomposed INF

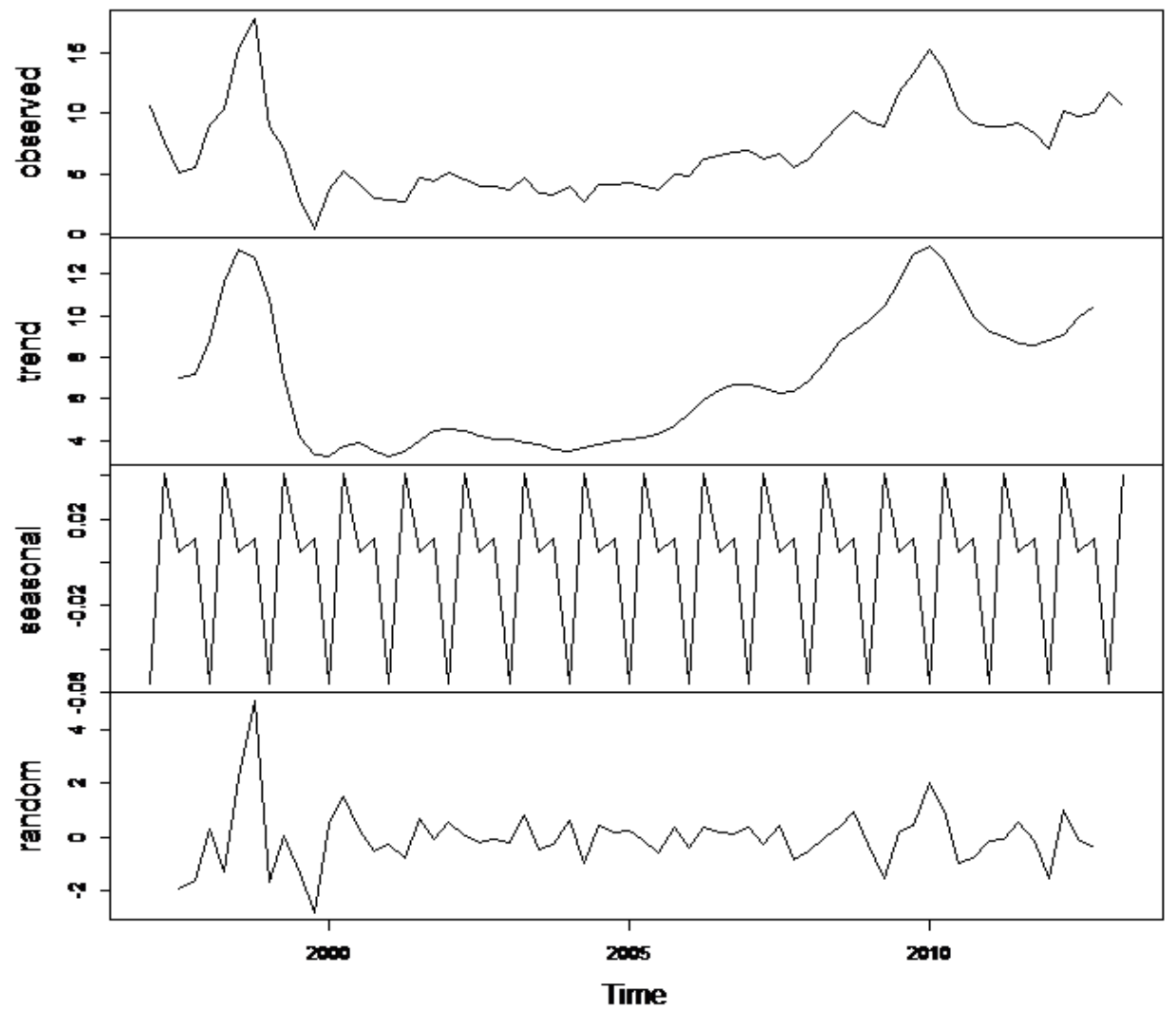

c. Indonesia

Decomposed RV 


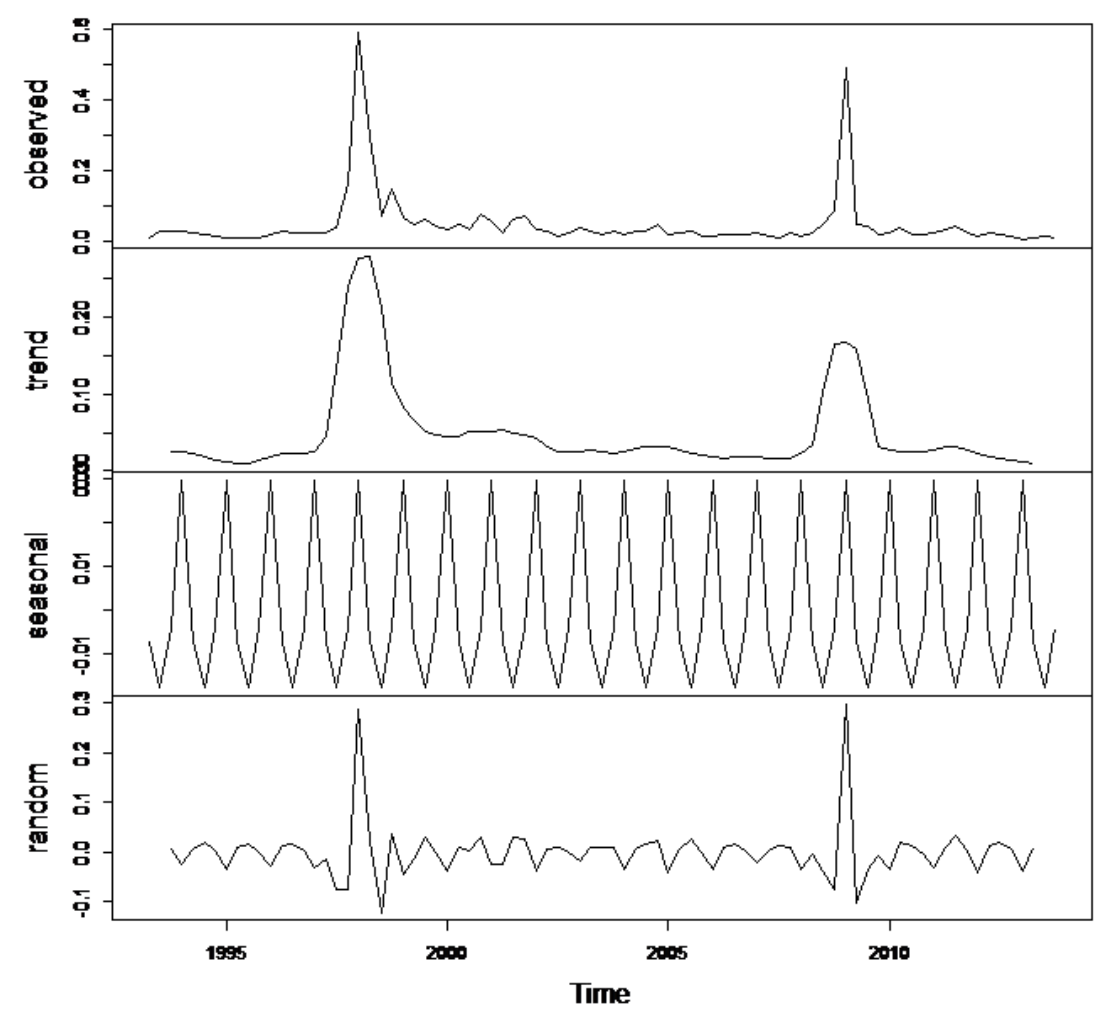

Decomposed GGDP

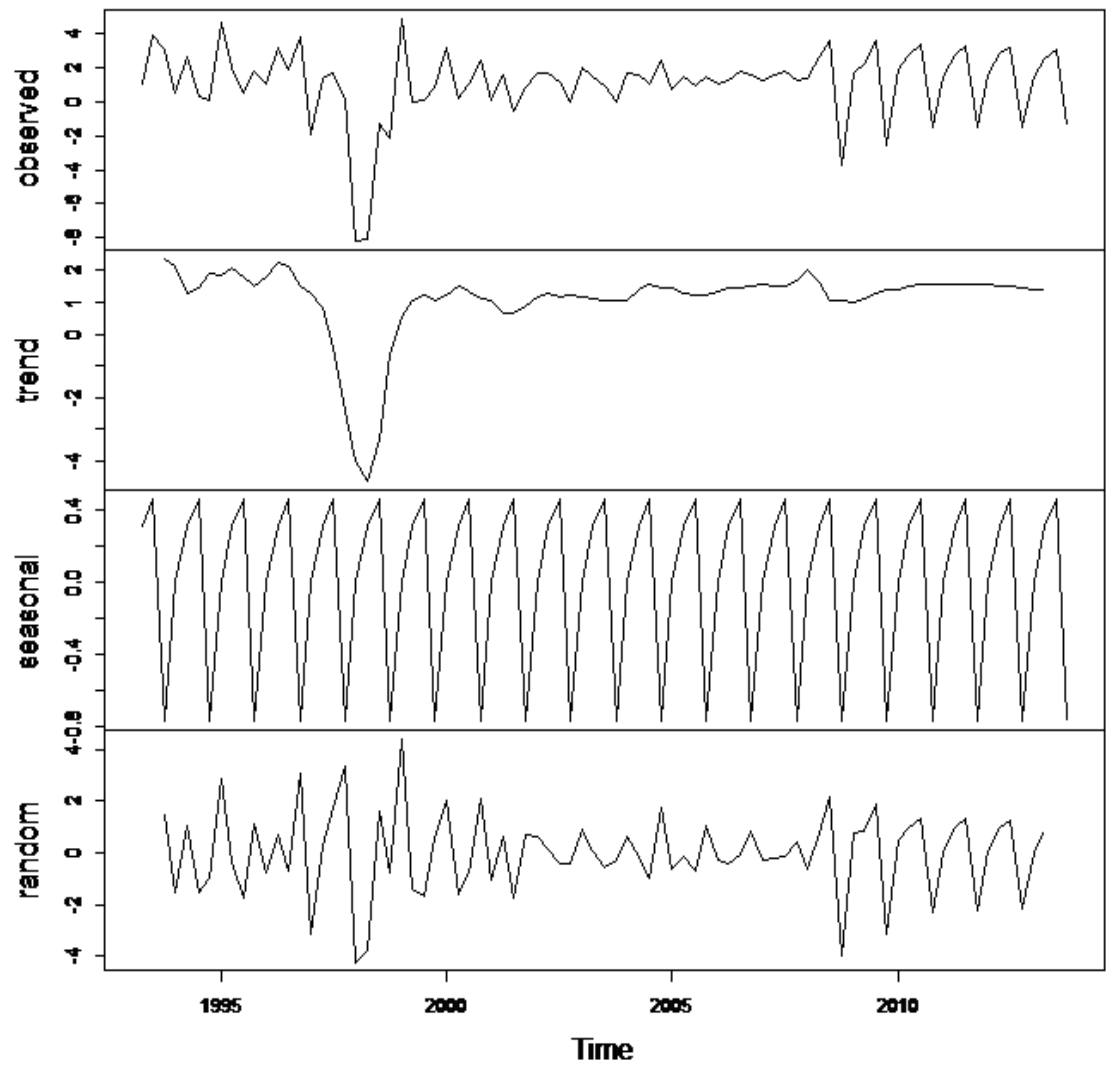

Decomposed INF 


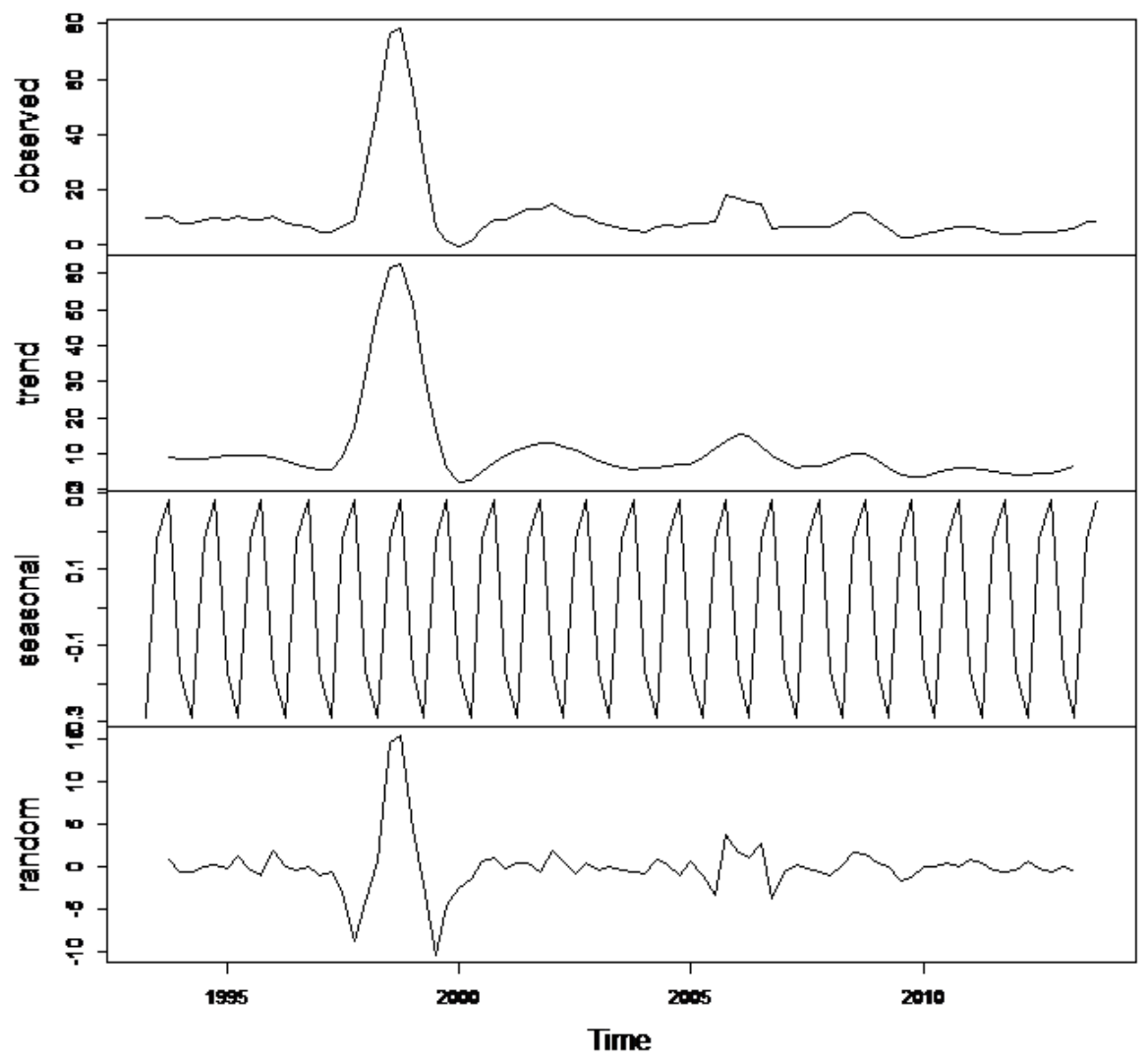

d. Malaysia

Decomposed RV

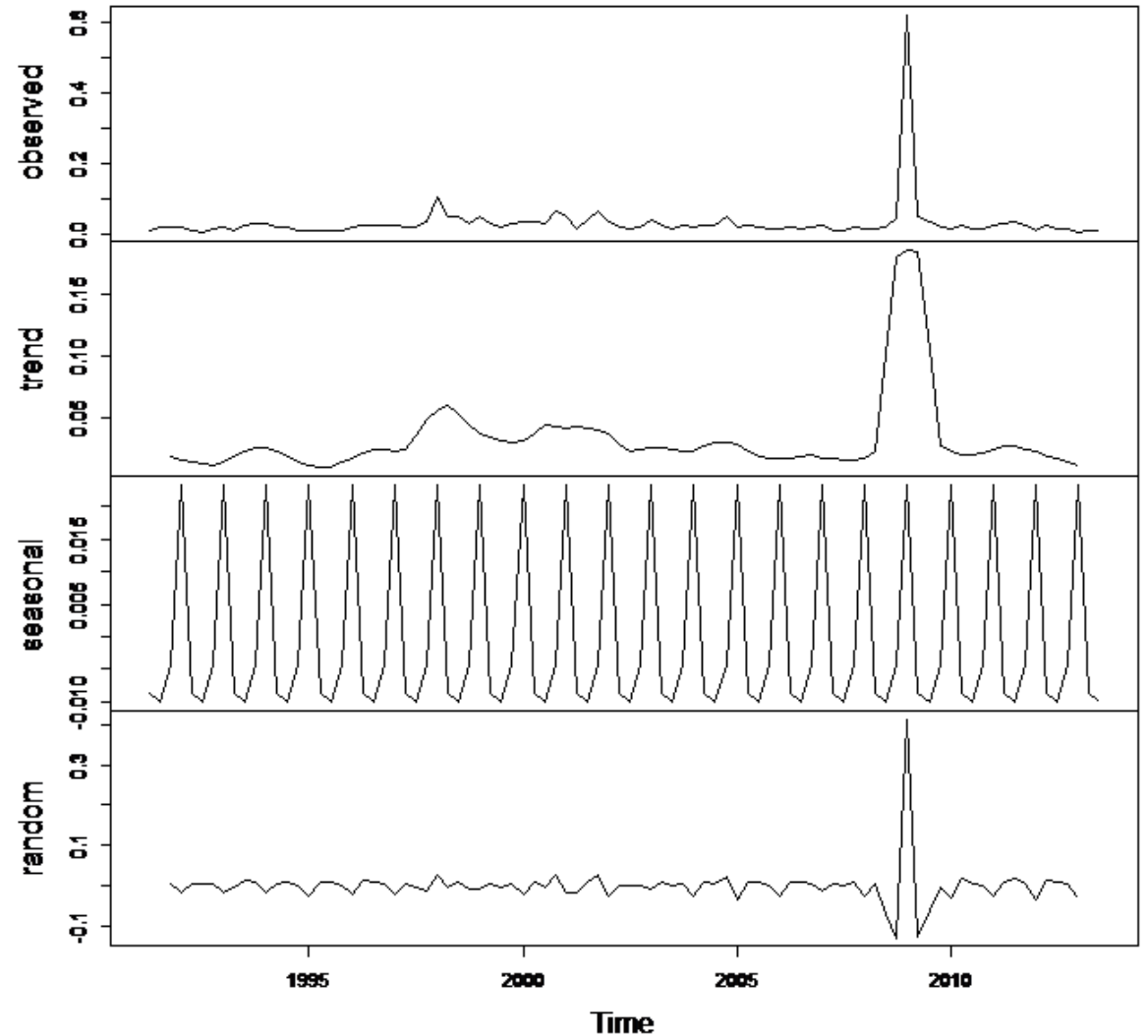

Decomposed GGDP 


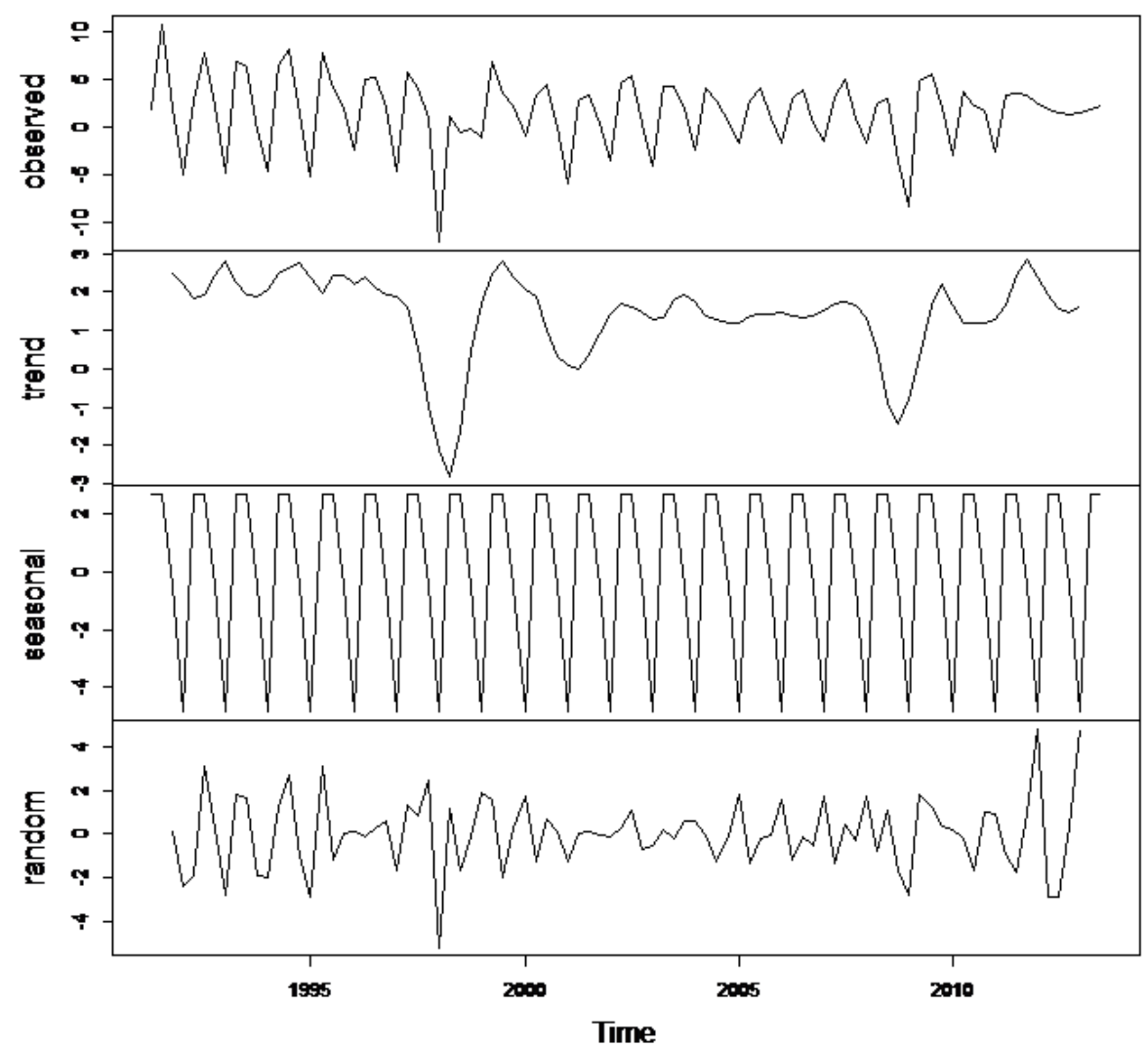

Decomposed INF

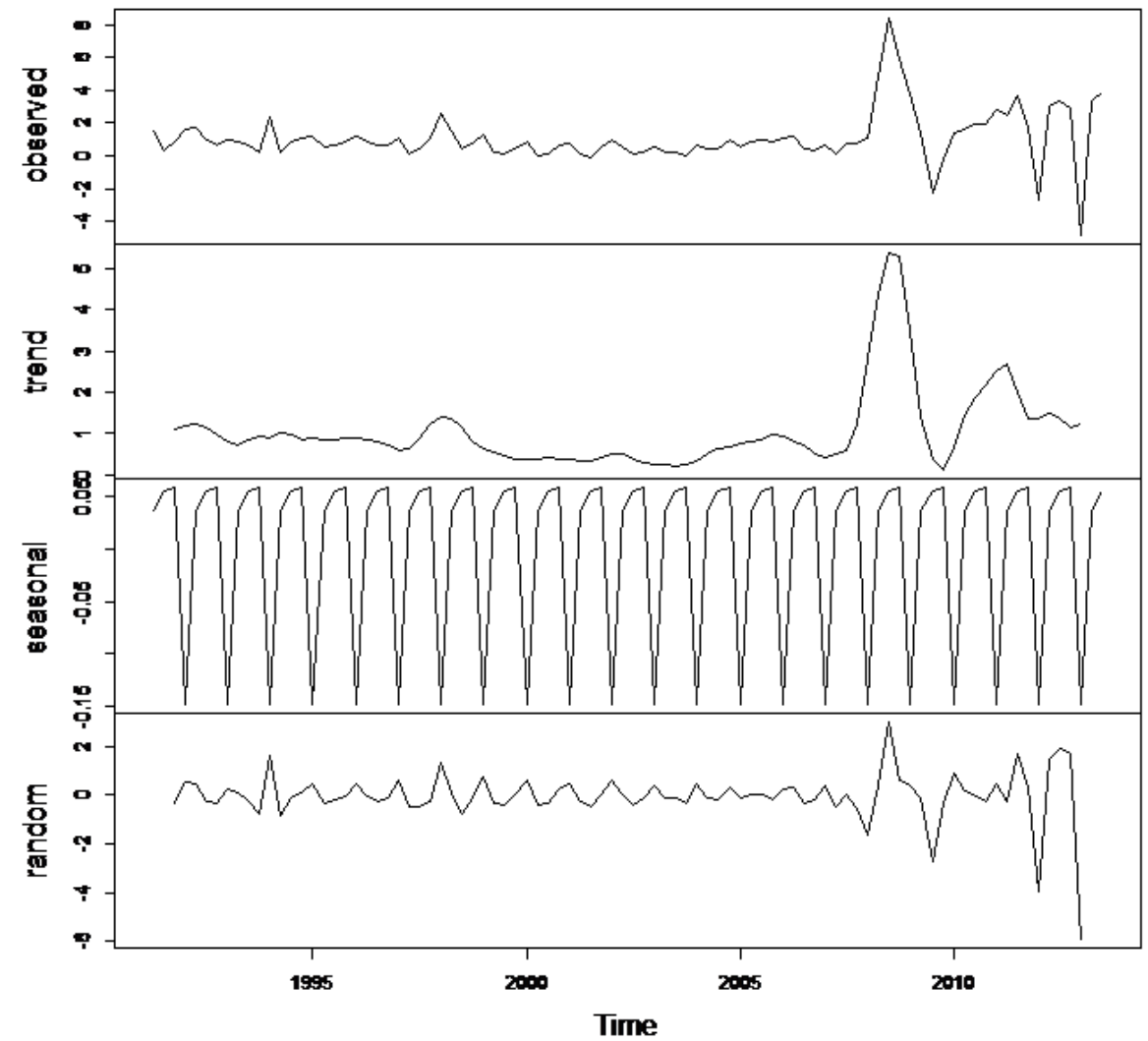

e. Philippines

Decomposed RV 


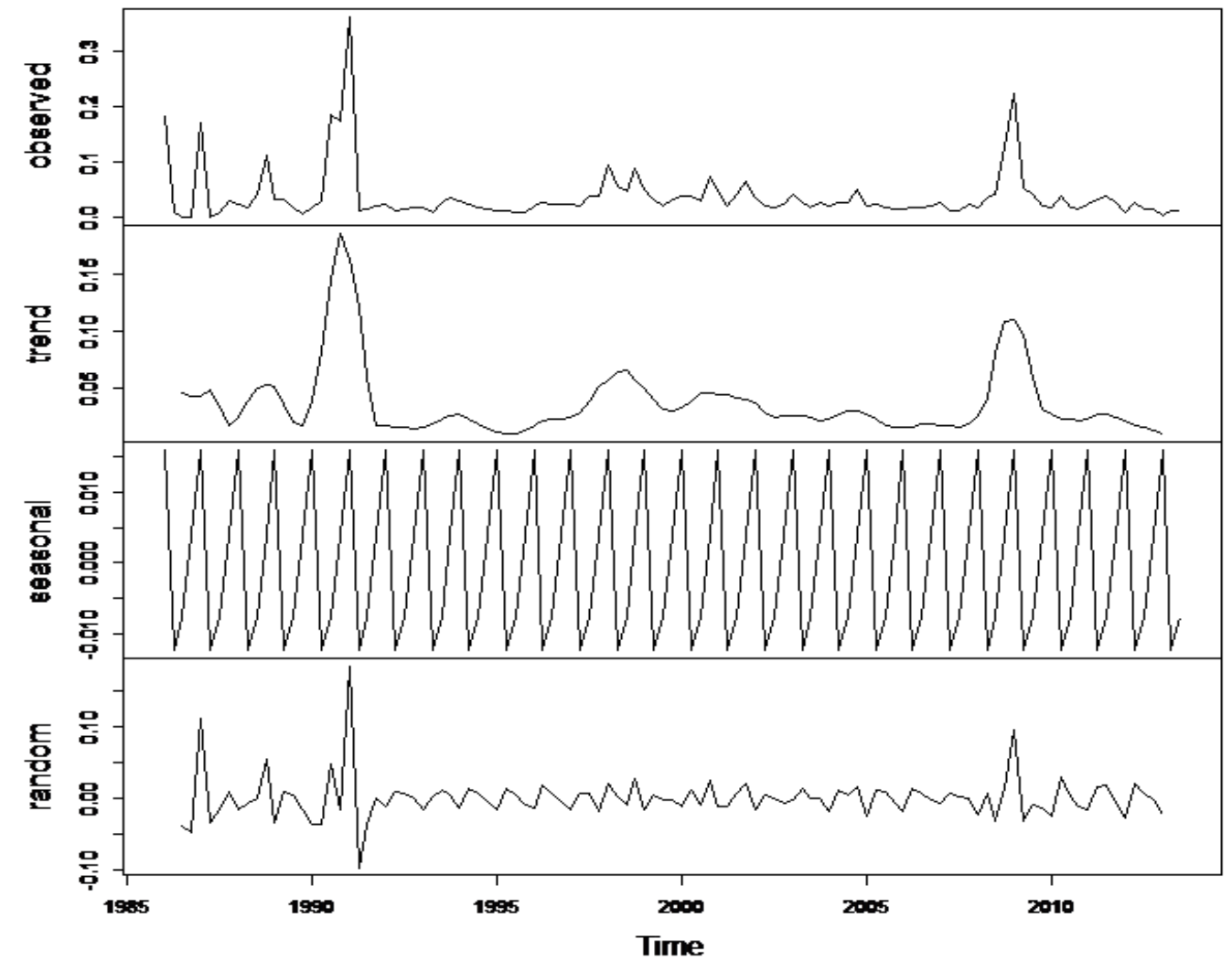

Decomposed GGDP

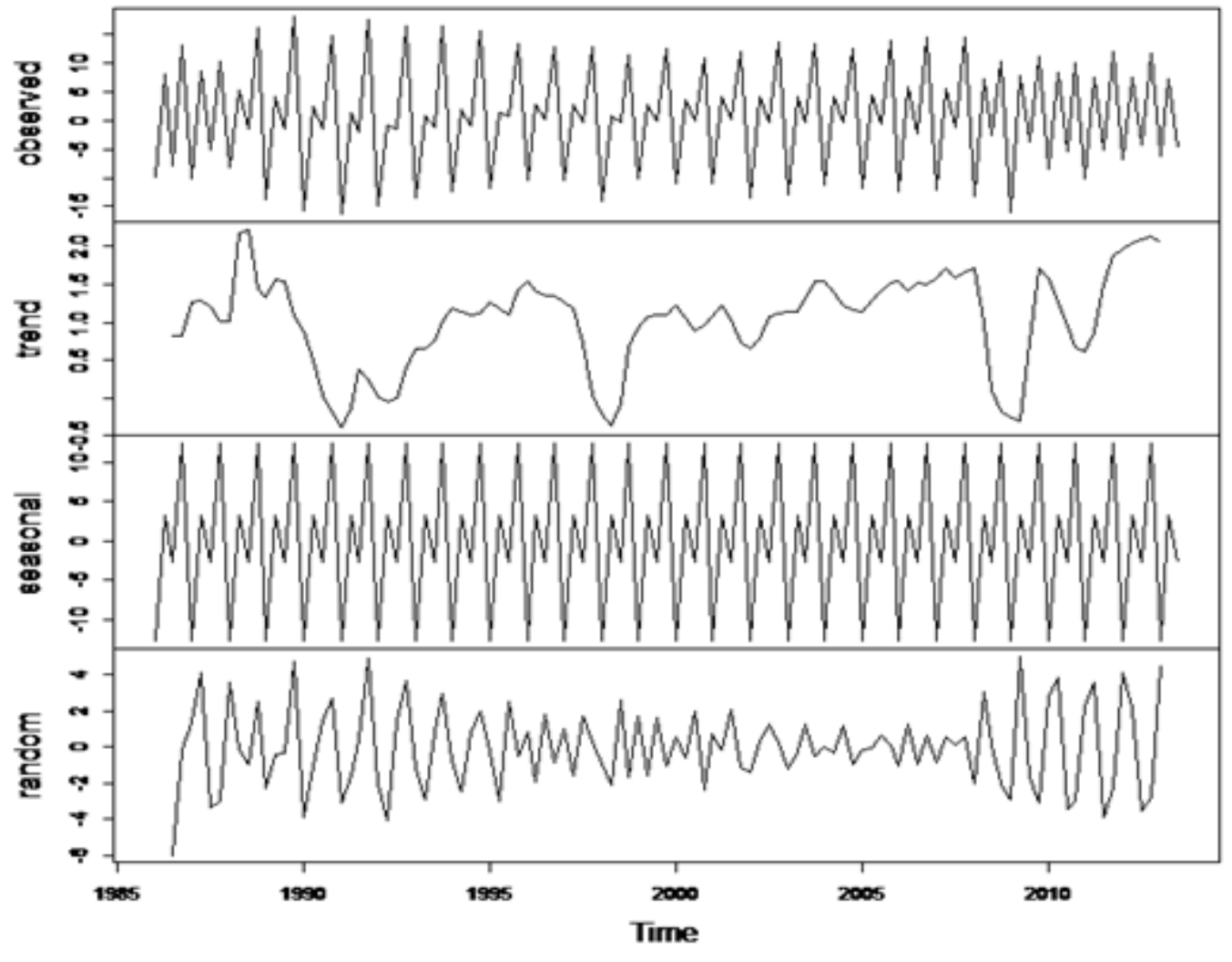

Decomposed INF 


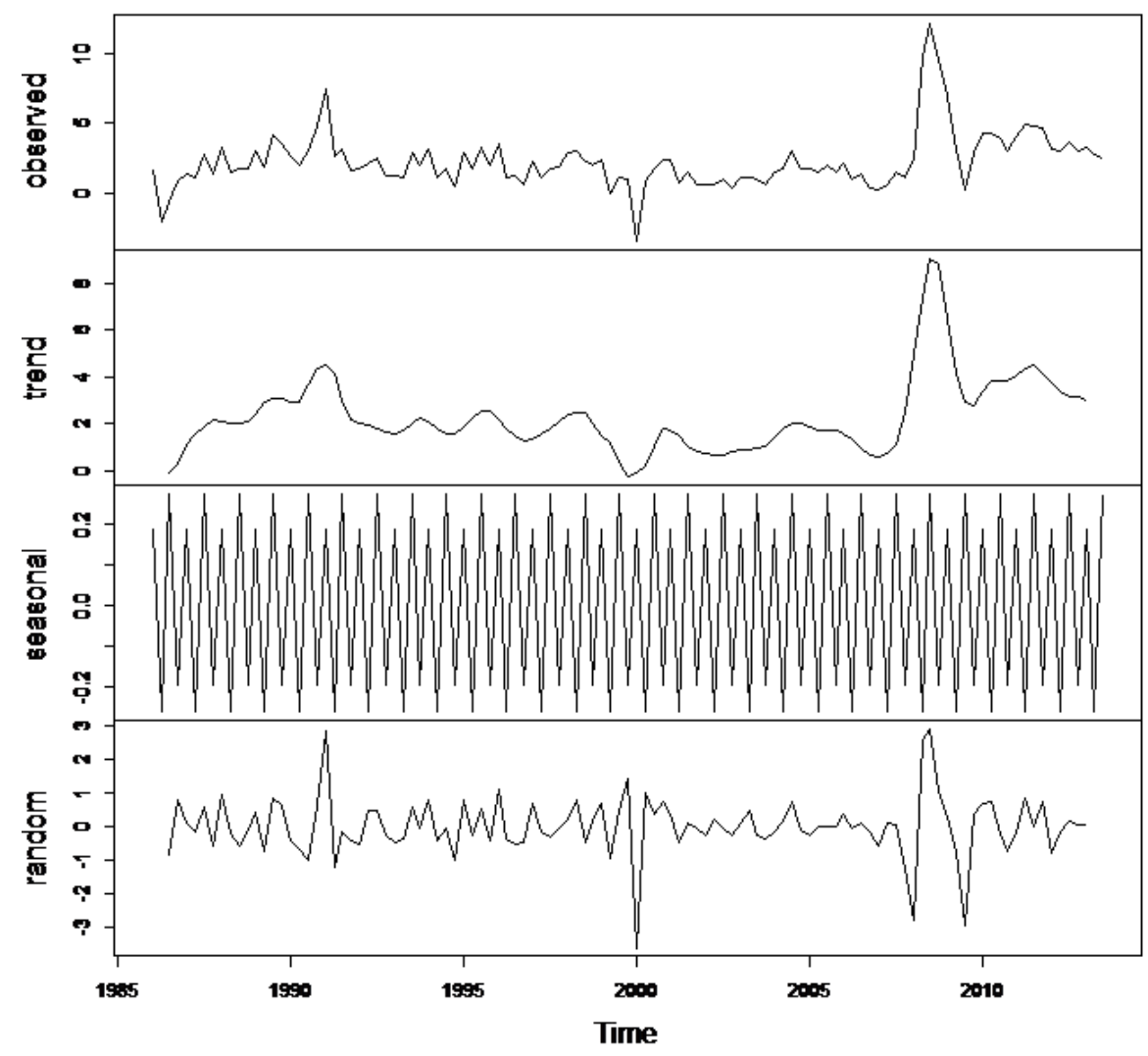

f. Thailand

Decomposed RV

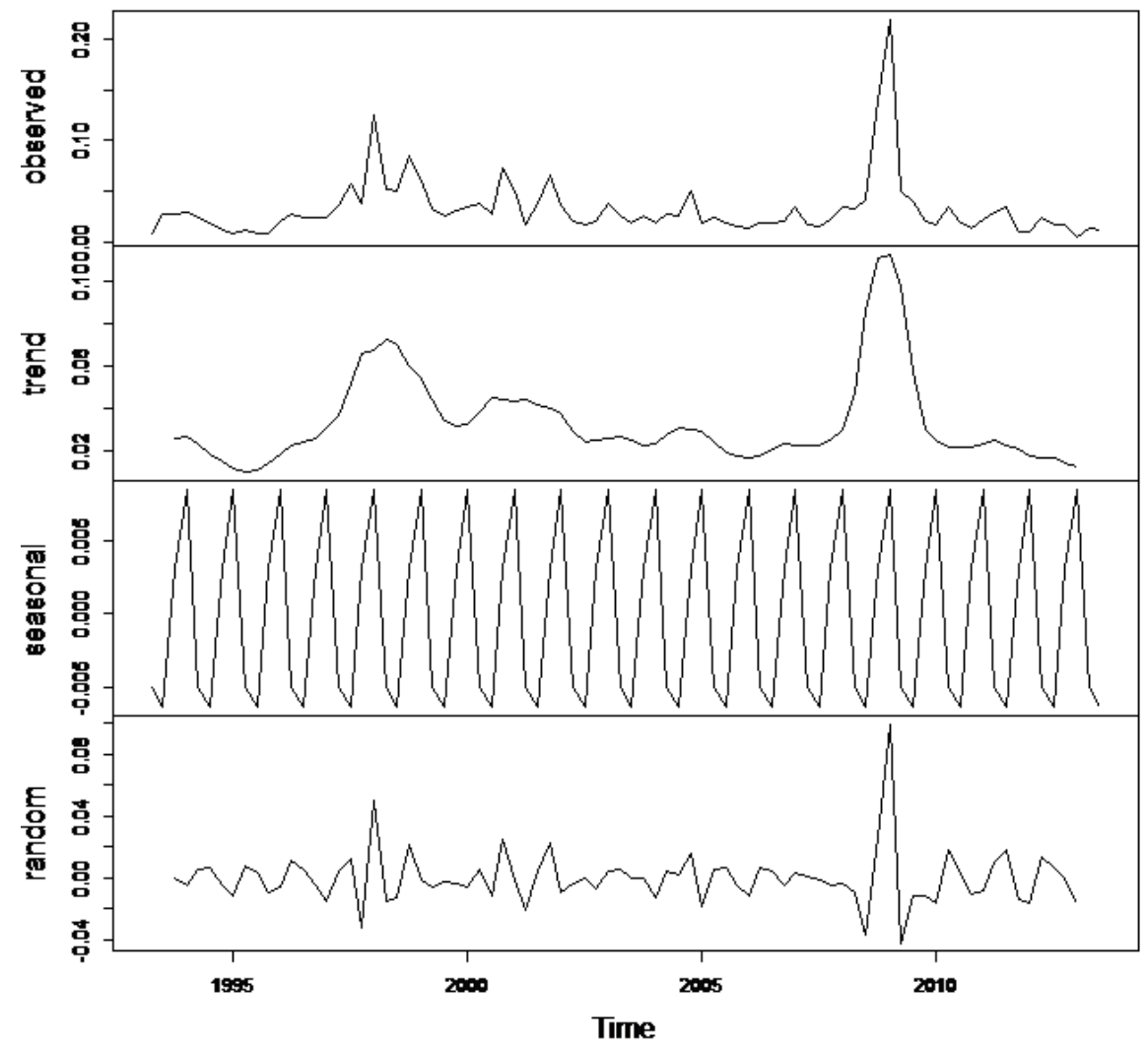

Decomposed GGDP 


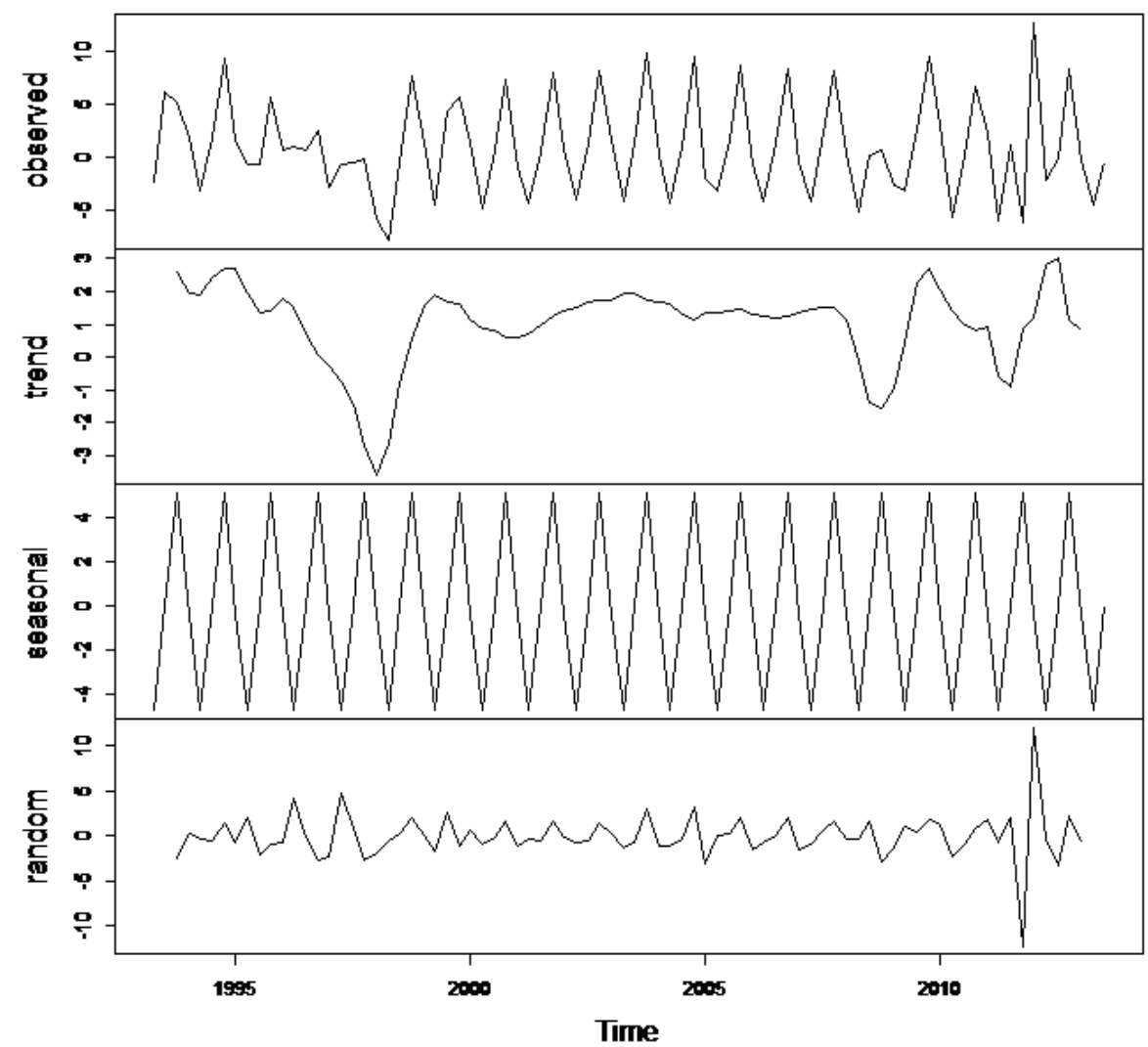

Decomposed INF

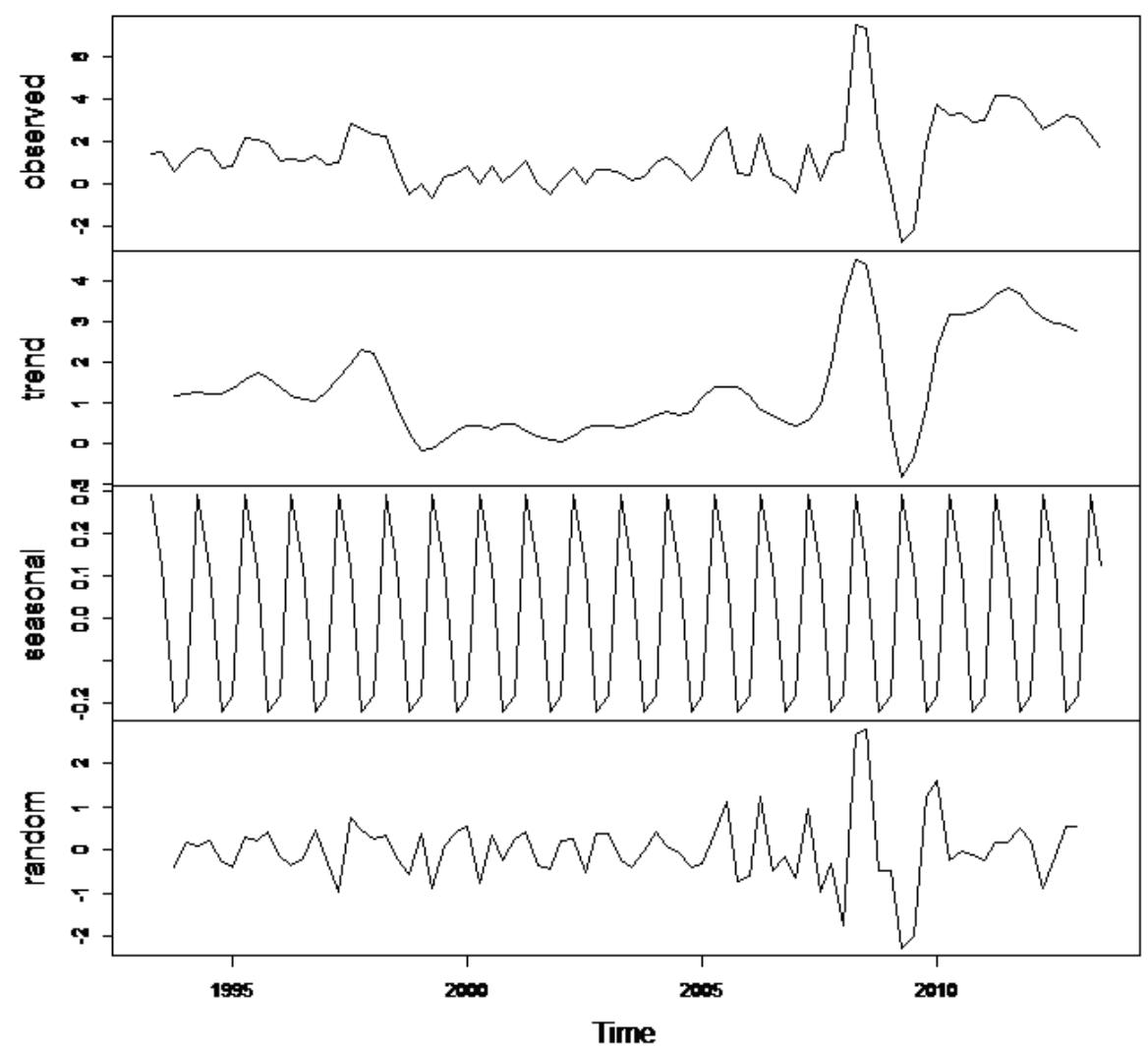

Note: RV, GGDP and INF stand for realized volatility for oil prices, GDP growth and inflation, respectively. 

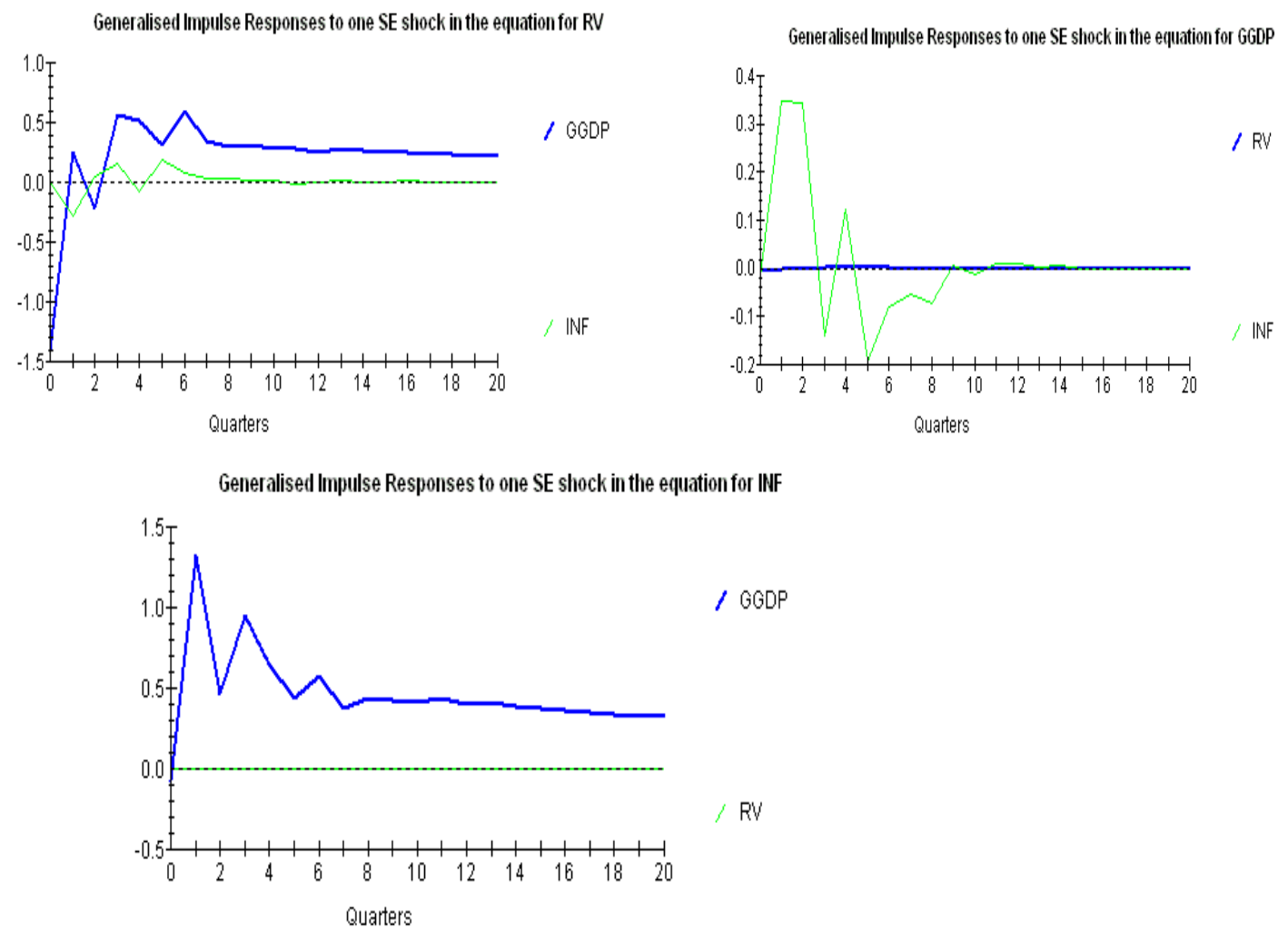

Appendix Figure 2: Findings from Generalized Impulse Response Function for India
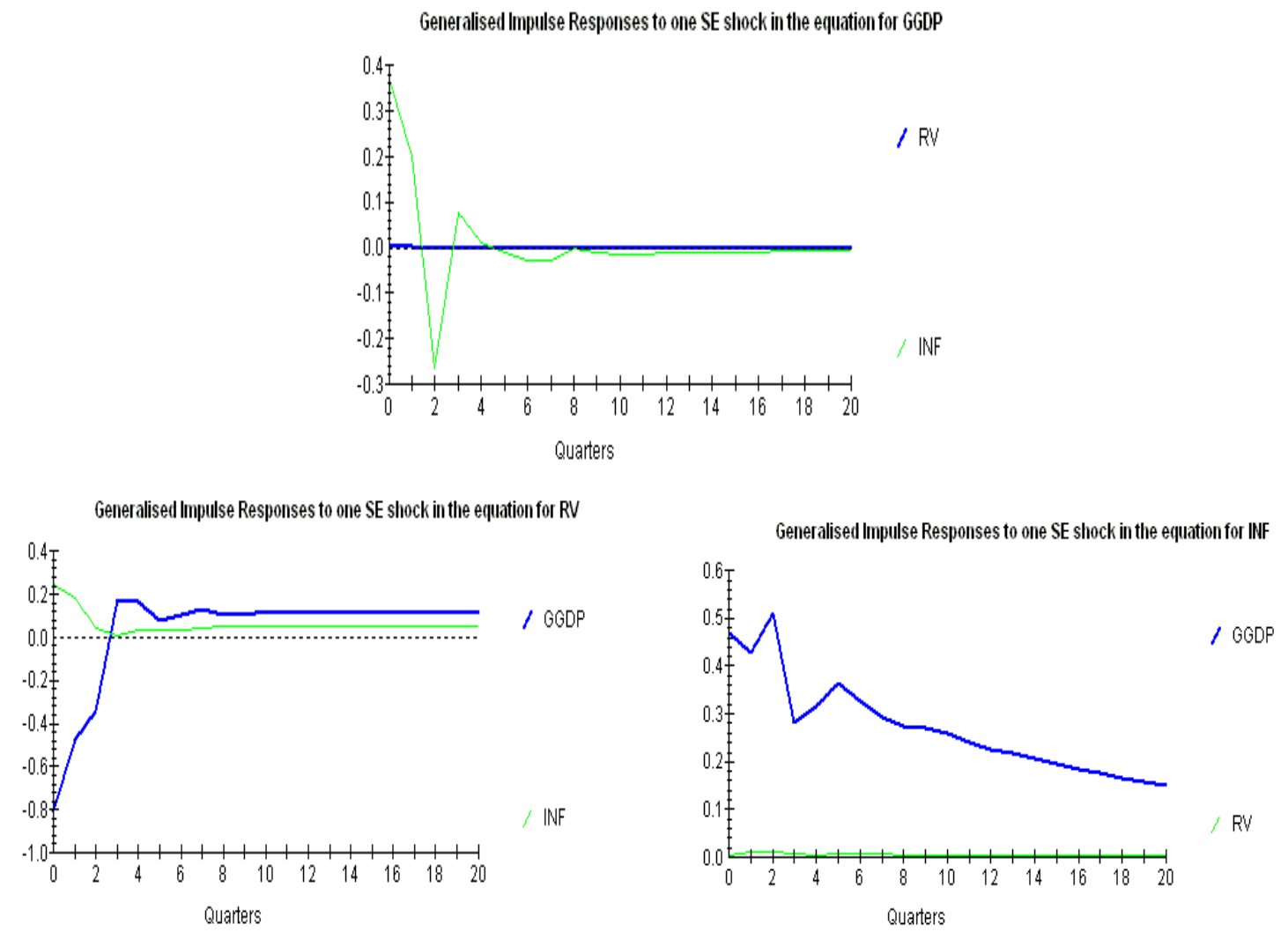

Appendix Figure 3: Findings from Generalized Impulse Response Function for Indonesia from 1993:2 to 2013:4 

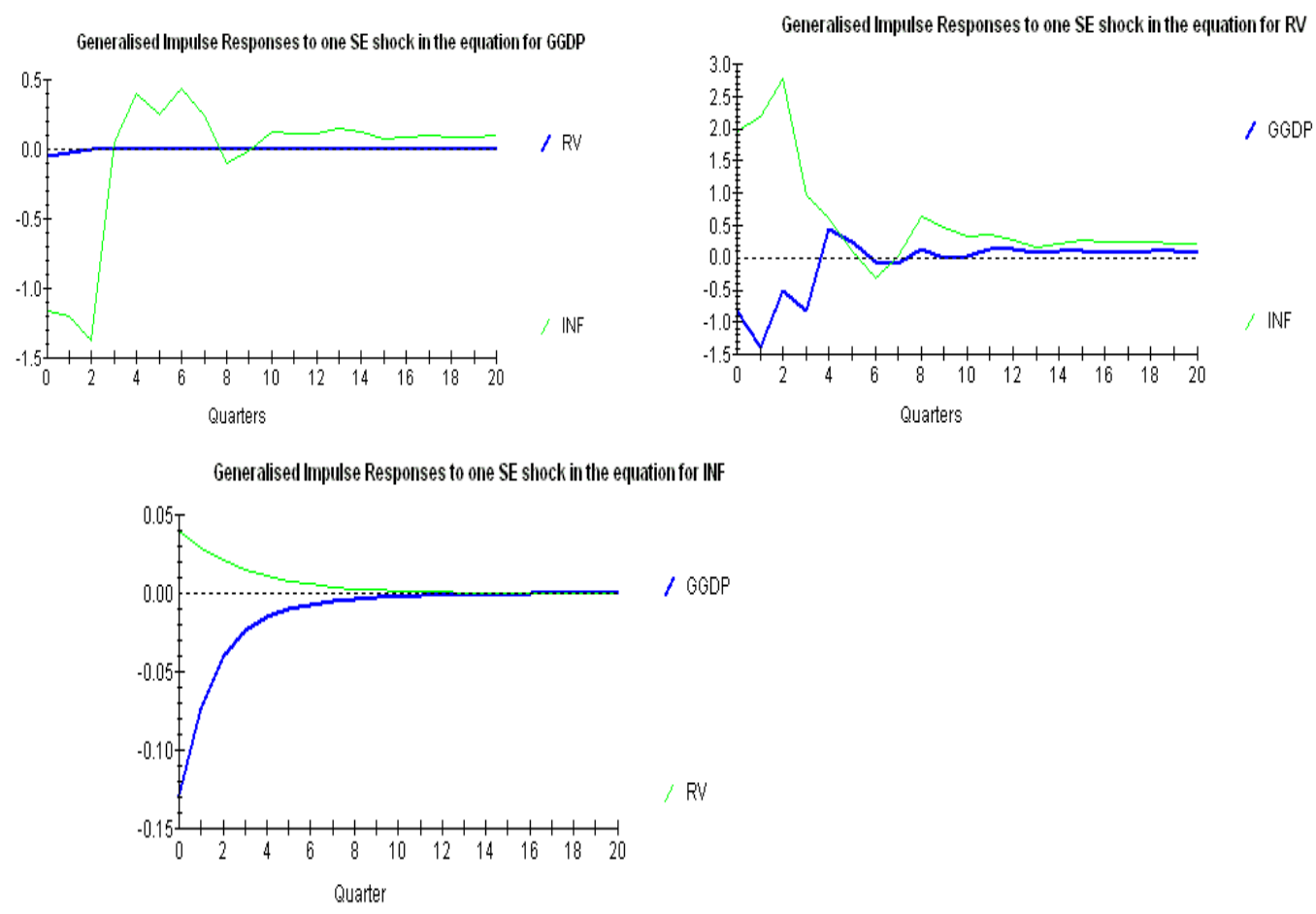

Appendix Figure 4: Findings from Generalized Impulse Response Function for Indonesia from 1998:4-

2013:4
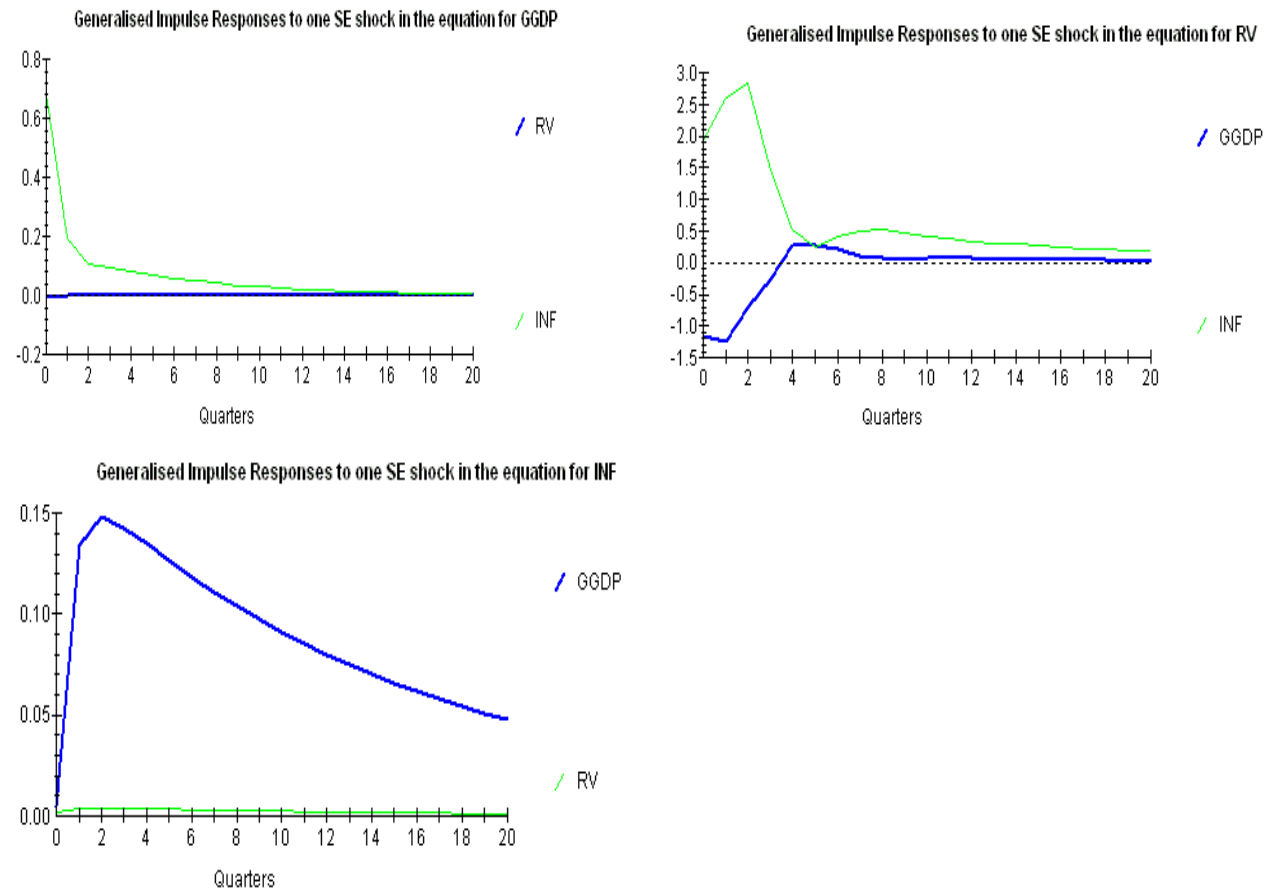

Appendix Figure 5: Findings from Generalized Impulse Response Function for Malaysia from 1991:2 to 2013:3 

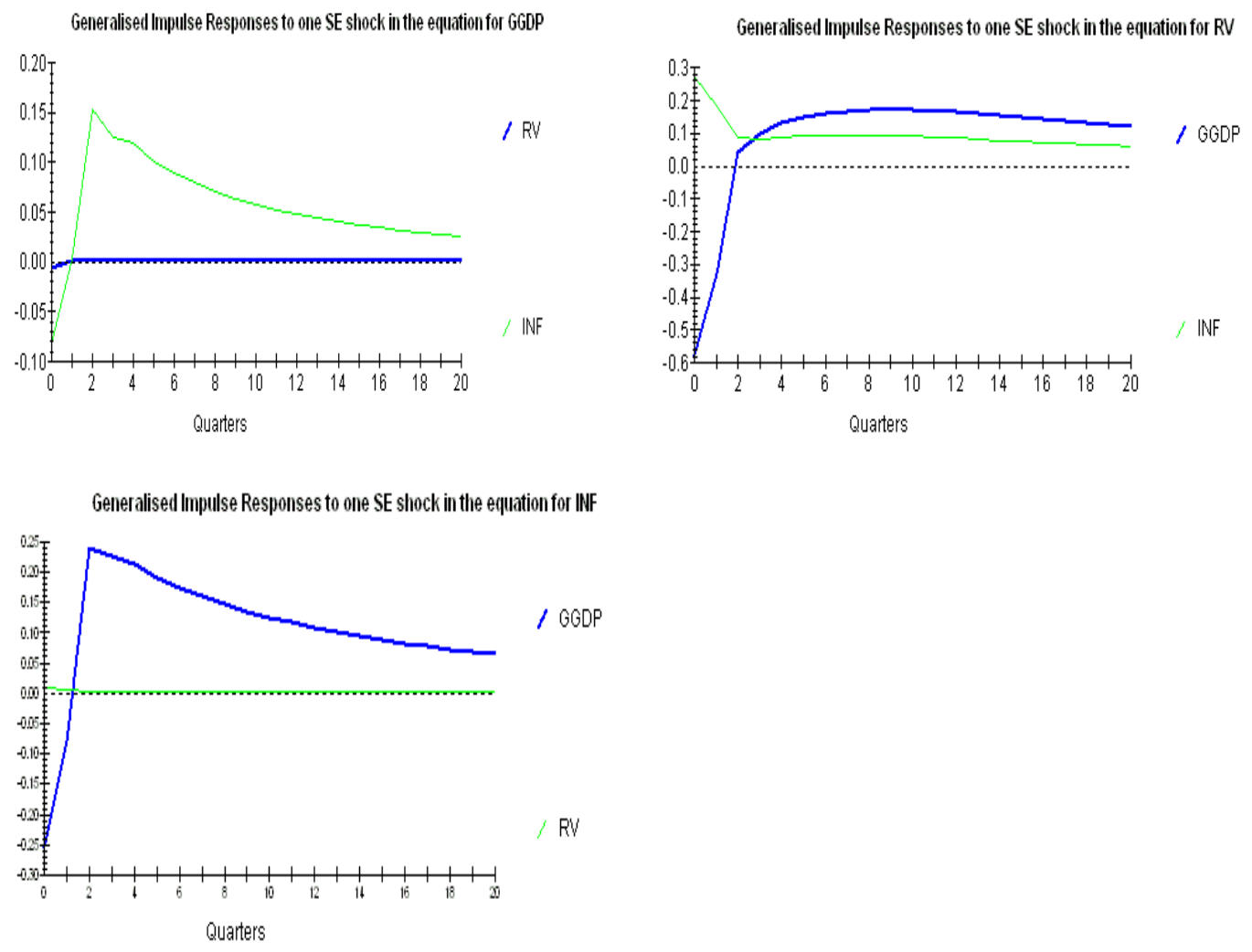

Appendix Figure 6: Findings from Generalized Impulse Response Function for Malaysia from 1998:4 to 2013:3
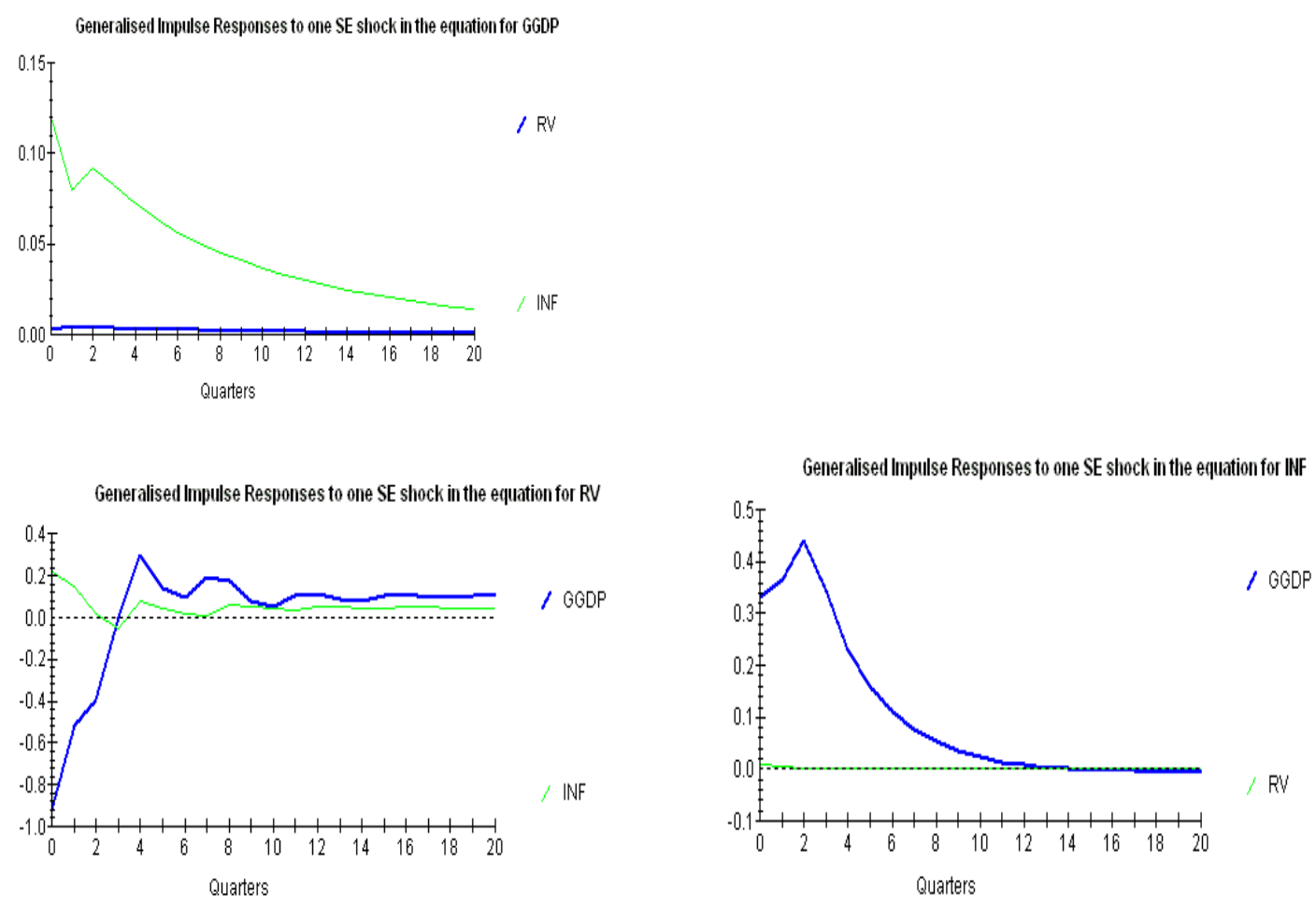

Appendix Figure 7: Findings from Generalized Impulse Response Function for Philippines 

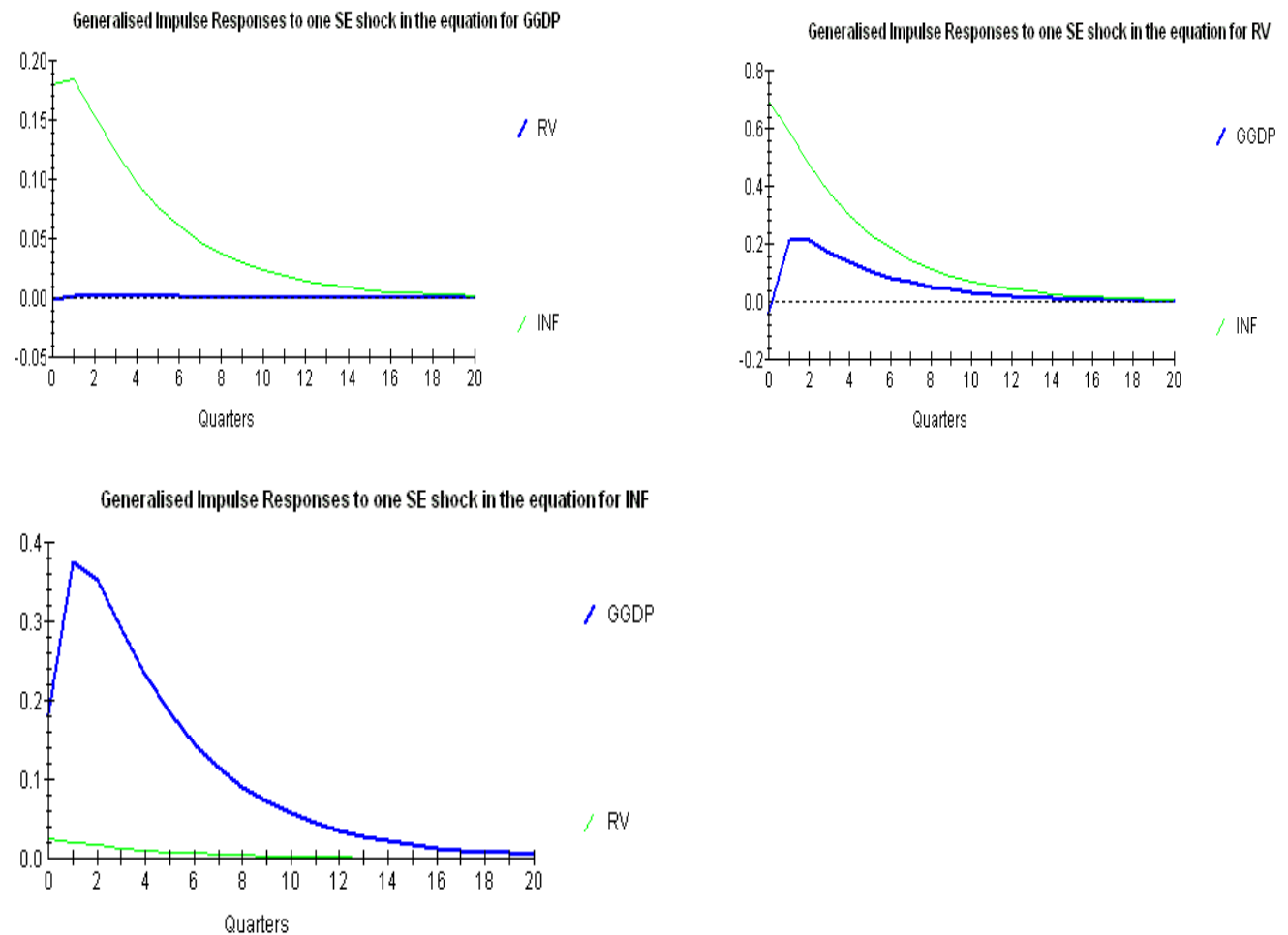

Appendix Figure 8: Findings from Generalized Impulse Response Function for Thailand from 1993:2 to 2009:1
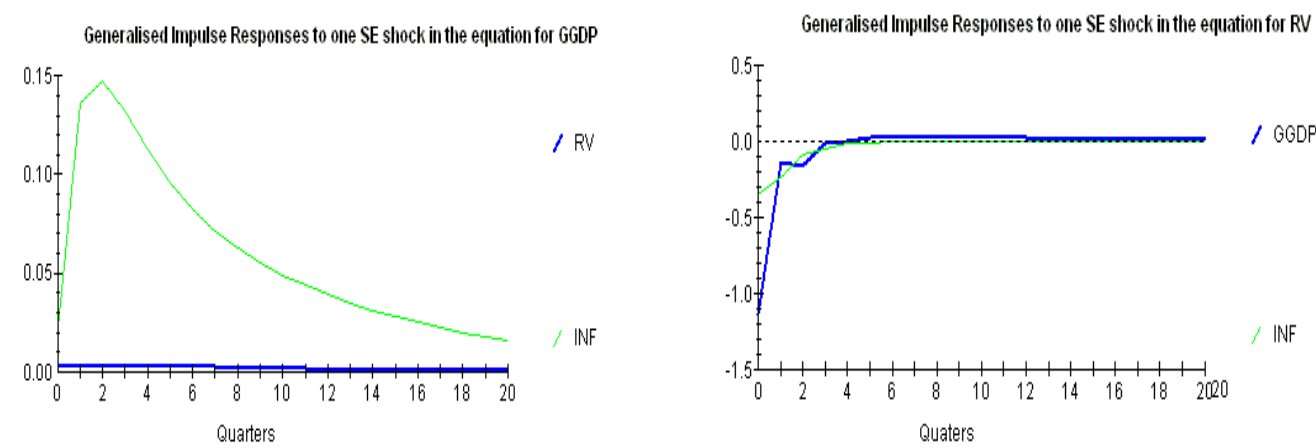

Generalised Impulse Responses to one SE shock in the equation for INF

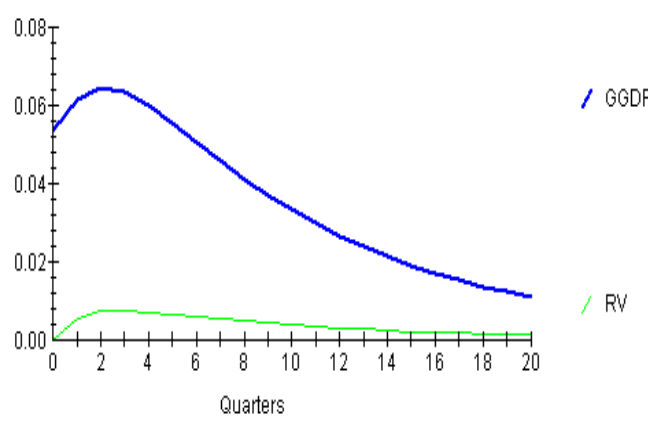

Appendix Figure 9: Findings from Generalized Impulse Response Function for Thailand from 1998:4 to 

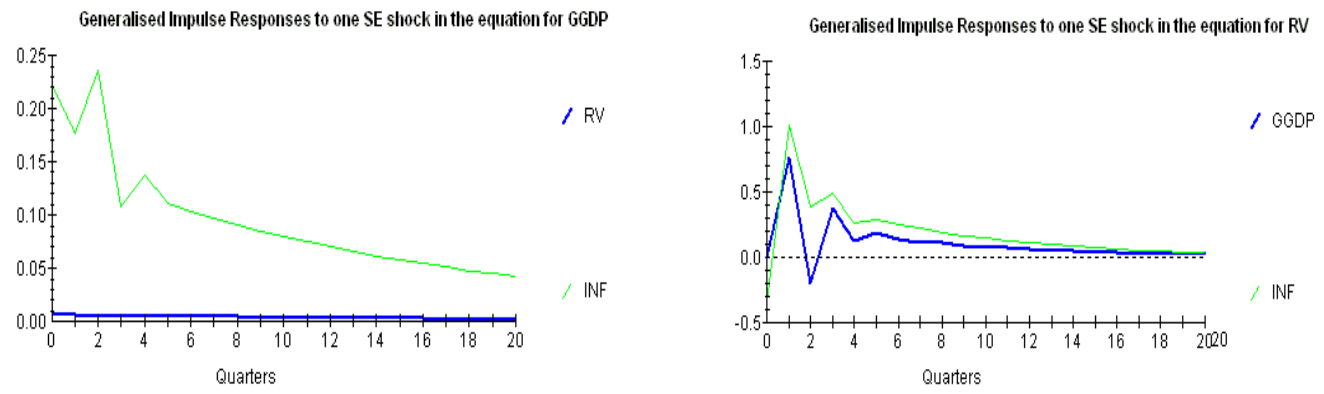

Generalised Impulse Responses to one SE shock in the equation for INF

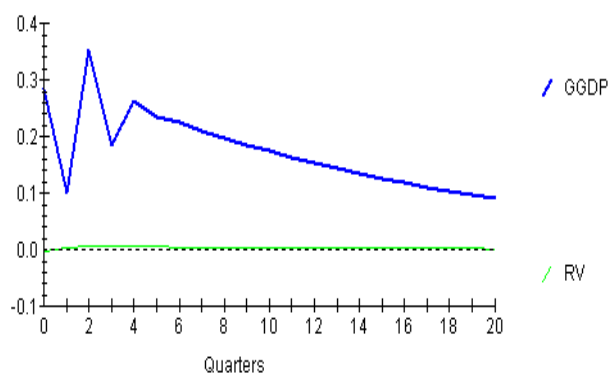

